\title{
An improved thermal model for characteristics analysis of multi-link ultra-precision press system ${ }^{\dagger}$
}

\author{
Enlai Zheng ${ }^{1,2,}$, Shilu Xie ${ }^{1}$, Jin Zhang ${ }^{1}$, Yue Zhu ${ }^{1}$, Xiao Zhao ${ }^{2}$, Xiangze Lin ${ }^{1}$ and Min Kang ${ }^{1}$ \\ ${ }^{1}$ Department of Mechanical Engineering, College of Engineering, Nanjing Agricultural University, Nanjing 210031, China \\ ${ }^{2}$ Engineering Sciences, Faculty of Engineering and the Environment, University of Southampton, Southampton SO17 1BJ, UK
}

(Manuscript Received March 24, 2017; Revised August 15, 2017; Accepted September 5, 2017)

\begin{abstract}
In traditional models, only the effect of temperature change of bearings on the heat generation power and thermal contact resistance is considered. But the effect of bearing stiffness and flexibility of crank shaft on the heat generation power is often neglected, thereby impairing the accuracy of the thermal analysis. Therefore, a better thermal model is demanded to accurately analyse the thermal characteristics of a Multi-link ultra-precision press system (MLUPPS). By combining the effect of stiffness of bearing and flexibility of crank shaft on the heat generation power, an improved thermal model of MLUPPS was developed in this work. The model was based on as-derived kinematic and dynamic equations of Multi-link transmission mechanism (MLTM) and flexible dynamic model of crankshaft-bearing system. The dimension chain of thermal error is constructed to analyse the dimensional error between the slider and the work table at the position of Bottom dead point (BDP). The developed thermal model of MLUPPS and its analysis results from this model are in good agreement with the measurement results, and that is more accurate than the traditional one. The simulation results reveal that the maximum temperature rise of MLUPPS occurs at the crank shaft, and the dimensional error between the slider and the work table at the position of BDP is due to thermal expansion fluctuation before the generation and conduction of heat power reaches balance. The temperature rise and thermal error of MLUPPS under different rotation speeds, piling forces and bearing stiffness were also studied.
\end{abstract}

Keywords: Multi-link; Press; Heat generation power; Thermal contact resistance; Error

\section{Introduction}

The Multi-link ultra-precision press system (MLUPPS), widely used in various field of automotive manufacturing, aerospace, home appliances, IT, etc, can solve such problems as tearing wrinkling, rejection rate, low service life of mold and fierce vibration, and noise during the stamping and deep drawing process of thin-walled parts. It can meet the process requirements of plastic processing, molding of higher toughness material and complex shape parts, composite molding and high precision molding. The rapid growth of demand for such small ultra-thin parts as the lead frame (IC and discrete device lead frame), precision connectors and the core of the micro-motor demands the MLUPPS to improve its processing efficiency and accuracy continuously. However, with the increase of stamping speed, friction-caused heat generation power of bearing and its corresponding parts increases dramatically, which could lead to the thermal drift of press and position change of upper and lower die. Thermal deformation

*Corresponding author. Tel.: +86 1345188 8670, Fax.: +86 2558606699

E-mail address: EnlaiZheng@njau.edu.cn

${ }^{\dagger}$ Recommended by Associate Editor Da-Cheol Ko

C KSME \& Springer 2018 of press system also reduces the accuracy of the relative position between the die and sheet metal and corresponding stamping accuracy, resulting in the dimensional and geometrical error of work piece. The thermal expansion is the main source of error for the press system and accounts for about $40 \% \sim 70 \%$ of the total error [1], which plays a significant role on its processing precision. Thus, it is critical to develop an appropriate thermal model of MLUPPS to gain insights to its thermal characteristics.

The thermal characteristics of the spindle system play a key role in the performance of machine tools. A number of scholars have conducted the investigation on the thermal models of spindle system. Bossmanns and $\mathrm{Tu}$ [2, 3] presented a thermal model to study the thermal distribution of high speed motorized spindle and also developed quantitative heat source models of the motor and bearings. Chen and Hsu [4] proposed a new thermal model with better accuracy and robustness that established the relationship between the thermal growth of spindle and the thermal displacements measured at some locations of the rotating spindle shaft. Lin et al. [5] developed an integrated model of motorized spindles with built-in motors to investigate the effect of the preload on bearing stiffness, centrifugal forces, gyroscopic moments on spindle shaft and the 
overall spindle dynamics. Based on the completed model of bearing [6], Li and Shin developed an integrated dynamic thermo-mechanical model of a spindle-bearing system to analyse the effect of bearing configuration on the thermodynamic behavior of high-speed spindles [7]. In order to simulate the thermal error of spindle for a CNC machine tool accurately, Zhao et al. [8] presented a method to calculate the convection heat transfer coefficient of the spindle surface based on the model of a flat plate with air flowing along it. Xu et al. [9] developed the complete thermal model of spindle for machine tools to simulate its temperature distribution and thermal expansion, which considers the effect of thermal contact resistance between two contact surfaces and the change of heat generation power with respect to temperature change of bearing. It has been proven more accurate than the traditional model. Creighton et al. [10] conducted a thermal analysis on the high-speed micro-milling spindle assembly using a Finite element method (FEM), and correlated the temperature rise to the resulting structural deformation. Holkup et al. [11] proposed a thermal-mechanical model of spindles with rolling bearings to analyze the thermal growth of spindle parts and transient changes in temperatures, deformations, the viscosity of the lubricant, and stiffness of bearing. Zahedi and Movahhedy [12] developed an integrated model of high speed spindles including viable models for the mechanical and thermal behavior of its main components such as bearings, shaft and housing, which treats the housing and shaft as six-degreeof-freedom Timoshenko beam elements and considers bearing as two-node elements. Zhao and Guan [13] proposed the thermal model of spindle system for machining center to perform both thermal and thermal-mechanical coupling analysis and simulated the heat dissipating capability of a cooling system. Lee et al. [14] established the thermal model of the highspeed spindle for machine tools to investigate the temperature distribution, temperature rise and thermal expansion at different rotation speeds by FEM. Ma et al. [15] proposed a threedimensional FEM model considering the effect of thermal contact resistance and bearing stiffness to perform the transient thermal-structure interactive analysis of motorized spindles. Du et al. [16] developed a thermal model of the motorized spindle to obtain the steady-state and the transient thermal field distribution and the corresponding expansion under the prescribed thermal load and boundary condition through ANSYS. Li et al. [17] established a thermal model of spindle system for machining center to simulate its temperature field and thermal deformation by FEM.

In order to investigate the influence of spindle system on the thermal characteristics of the entire machine structure, there have been numerous efforts to develop thermal models of machine tools. Kim et al. [18] presented a thermal model of machine tools with a linear motor operated under high speed and identified its thermal deformation characteristics. Shen et al. [19] developed a thermal model for grinding in order to solve transient heat transfer problems by the Finite difference method (FDM) and studied the effects of work piece size, feed rate and cooling boundary conditions. To predict the change of temperature distribution, Wang et al. [20,21] established the thermal model of a crank press by FEM and proposed the thermal error dimension chain method to analyze its thermally induced errors of press structure. Maier and Zaeh [22] proposed a method for the holistic modelling of process effects for lathe including process heat, cutting forces and increased load on feed and main drives. Tang and Jia [23] established a thermal model of connecting rod for press system to analyze its temperature rise and thermal balance time. Chen et al. [24] and $\mathrm{Hu}$ et al. [25] developed the thermal model of press machine to predict its temperature filed distribution and thermal error under maximum load operation condition. Chval [26] performed a thermal analysis on the influence of temperature change on the durability of frame structure and machining accuracy of forging machine. Zheng et al. [27] proposed an improved thermal model of press system incorporated with the thermal contact resistance between two contact surfaces and the effect of temperature change for bearings on heat generation power to analyze its temperature distribution and thermal deformation. Kong [28] established a thermal model to simulate the temperature distribution and thermal expansion of the spindle system by FEM, and studied the thermal characteristics of whole machine.

The current thermal models of press systems often neglect the effect of stiffness of bearings and flexibility of crank shaft on the heat generation power, which impairs the analysis precision of thermal characteristics and corresponding error. In order to improve the analysis precision, an improved thermal model of MLUPPS is proposed in this work, which incorporates the effect of stiffness of bearing and flexibility of crank shaft on the heat generation power into the traditional models. The temperature change history and thermal dimension error between slider and work table at the position of BDP are studied for MLUPPS under piling condition by the FEM. Furthermore, the temperature rise of the press system and thermal error under different rotation speeds, piling forces and stiffness of bearings are also investigated.

This paper is organised as follows: The configuration and transmission principle of the MLUPPS are described briefly in Sec. 2. Dynamic analysis of crankshaft-bearing system is implemented in Sec. 3. A thermal model of MLUPPS is proposed in Sec. 4. The temperature profile with time and dimension error between slider and work table at the position of BDP for MLUPPS are analysed and discussed in Sec. 5, and the proposed thermal model is then validated with experimental results. Sec. 6 summarizes the proposed thermal model and the conclusions as well as future work. In appendix sections, the kinematic and dynamic equations of the MLTM are derived.

\section{Physical description}

As shown in Fig. 1, the main structure of MLUPPS is composed of the upper beam, column, lower beam, pull rods, base 
1. Upper beam, 2-crank shaft, 3-main linkage, 4-lower connecting slider, 5-swing link, 6-supporting link, 7-linkage, 8-toggle link, 9-connecting rod, 10-main slider, 11-auxiliary linkage, 12-balance slider, 13-pull rod, 14-column, 15-base

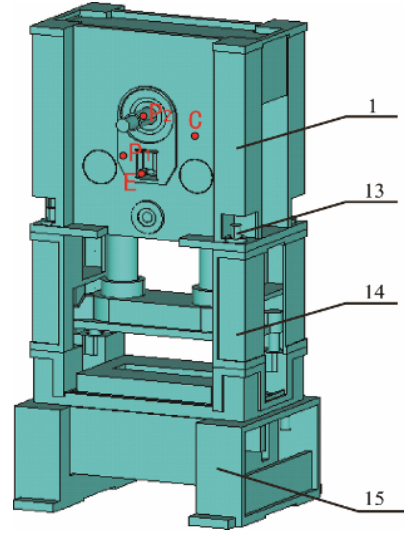

Fig. 1. Solid model of the MLUPPS.

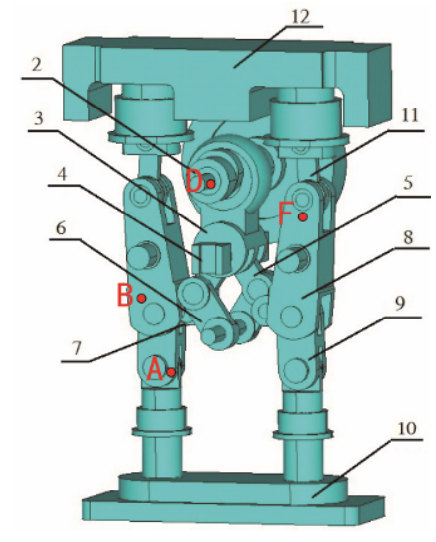

Fig. 2. Solid model of the MLTM.

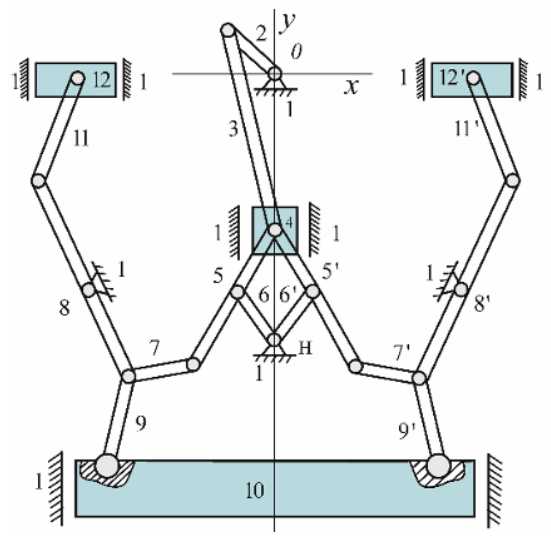

Fig. 3. Transmission principle of the MLTM. and the MLTM. The solid model and transmission principle of the MLTM are shown in Figs. 2 and 3, respectively. The slider-crank mechanism (Crank shaft 2, linkage 3 and slider 4) is combined with rhombic driving mechanism (Swing link 5 and 5', fulcrum link 6 and 6') and elbow-bar mechanism (Linkage 7, 7', 9 and 9', elbow bar 8 and 8') in series, which constitutes the MLTM. When the power of the motor is transmitted to the crank shaft through belt transmission and the crank shaft 2 rotates around point $O$, the slider 4 will be driven by linkage 3 and moves reciprocally in the vertical direction. The swing links 5 and $5^{\prime}$ are hinged to the slider 4 . Similarly, the fulcrum links 6 and $6^{\prime}$ are hinged to point $\mathrm{H}$ of press frame, which can swing around point $\mathrm{H}$. The swing links 5 and $5^{\prime}$ moves in planar under the action of slider 4 , fulcrum links 6 and $6^{\prime}$ together, which forces the links 7 and $7^{\prime}$ to drive the elbow bars $8,8^{\prime}$ and links 9, 9'. The links 9 and 9' are hinged to slider 10 that also moves reciprocally in the vertical direction along the guide rail and can manufacture the metal parts close to target shapes. In order to balance the inertia force of the main mechanism, additional weight $(12,12$ ') is designed. The working time of the MLUPPS under load is short during the whole cycle and the rest of the cycle under no-load is for the empty trip. The function of the flywheel for the MLUPPS is to make the motor operate under uniform load and consume energy with higher efficiency.

\section{Dynamic model of crankshaft-bearing system}

The heat sources of upper beam for the press system are mainly distributed on the bearings of crank shaft system. In order to investigate the effect of bearing stiffness on the thermal error of the whole press system, it is essential to develop the dynamic model of crankshaft-bearing system to calculate the heat generation power.

\subsection{Traditional model of crankshaft-bearing system}

The traditional mechanical model of crankshaft-bearing sys-

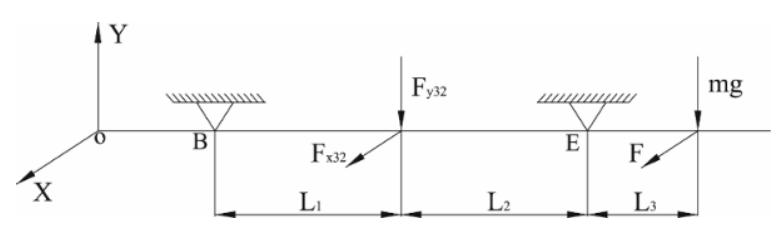

Fig. 4. Traditional mechanical model of crankshaft-bearing system.

tem for the MLTM is shown in Fig. 4, which simplifies the crank shaft as a simple supported beam [29].

The force on the crank shaft, as a result of the belt, can be calculated as follows:

$$
F=P_{m} d_{1} / v
$$

Upon releasing the constrains of the two bearing seats, the load spectrum acting on the points B and E can be expressed based on the force and moment balance relationship as:

$$
\left\{\begin{array}{l}
F_{b x}=\frac{F L_{3}-F_{x 32} L_{2}}{L_{1}+L_{2}} \\
F_{b y}=\frac{L_{3} m g-F_{y 32} L_{2}}{L_{1}+L_{2}} \\
F_{e x}=-\frac{F L_{1}+F L_{2}+F L_{3}+F_{x 32} L_{1}}{L_{1}+L_{2}} \\
F_{e y}=-\frac{L_{1} m g+L_{2} m g+L_{3} m g+F_{y 32} L_{1}}{L_{1}+L_{2}} .
\end{array}\right.
$$

When the press is manufactured, it is common to perform factory inspection and test under the piling condition. Therefore, the JL75G-60 MLUPPS under piling condition is taken as a numerical simulation example in this work. In the current analysis, the press load under piling condition, as a result of the collision between the upper and lower dies, can be described as a rectangular shape of pulse load (Fig. 5). When the upper die contacts with the lower die, impact force reaches the 


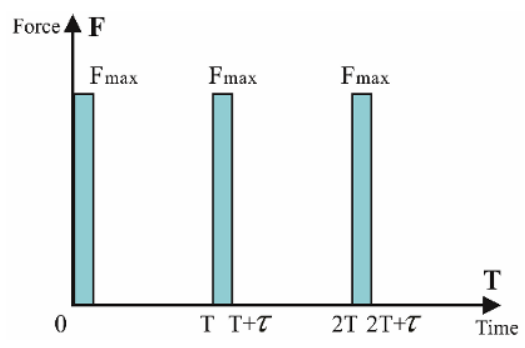

Fig. 5. The piling load.

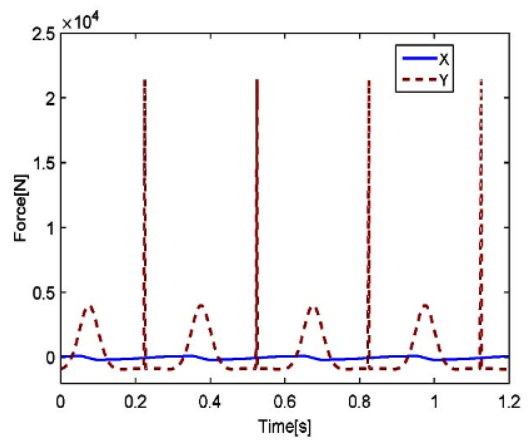

(a)

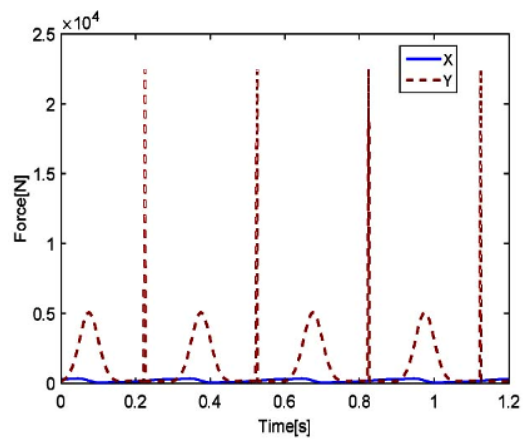

(b)

Fig. 6. Load spectrum of points in crank shaft system: (a) B; (b) E.

maximum value $F_{\max }$, and after the time lasts $\tau$, the impact load disappears once the upper die is separated from the lower die. The piling load can be expressed as:

$$
P(t)=\left\{\begin{array}{cl}
F_{\max } & 0 \leq t<\tau \\
0 & \tau \leq t<T .
\end{array}\right.
$$

The simulation parameters of the MLTM are listed in Table 1. By substituting the parameters into the Eq. (2), the load spectrum from the traditional model under piling condition can be obtained shown in Fig. 6 .

Fig. 6 shows that under piling condition, the load spectrum between the crank shaft and the bearing seat of the upper beam exhibits a form of the periodic pulse wave as a result of the giant impact during piling process. When the piling process finishes, the load spectrum exhibits a form of the periodic sine wave, which may be attributed to the inertia force induced from the MLTM. The peak value of the load spectrum

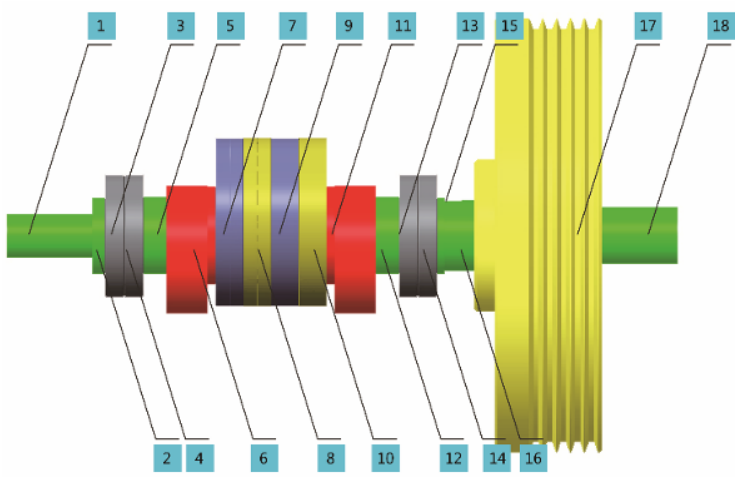

Fig. 7. Solid model of structure for the crankshaft-bearing system.

at point $\mathrm{B}$ along the $\mathrm{X}$ and $\mathrm{Y}$ directions are $86.11 \mathrm{~N}$ and $21.4 \mathrm{kN}$, respectively. The peak value of the load spectrum at point $\mathrm{E}$ are $332.9 \mathrm{~N}$ and $22.46 \mathrm{kN}$.

\subsection{Improved model of crankshaft-bearing system}

When the MLUPPS operates under high-speed condition, the thermal deformation produces as a result of heat generation from friction between the ball and the groove of the antifriction bearing, between the slider and the guide rail. It affects the relative dimension precision between the slider and work table, and reduces the stamping precision of press system and product quality. The solid model of the structure for the crankshaft-bearing system is shown in Fig. 7 and the FE model of crankshaft-bearing system is established (Fig. 8). The parameters of the crank shaft system are listed in Table 1.

Fig. 9 shows the diagram of the crank shaft with the pulley. It is assumed that the disk is fixed and its rotational effect is neglected since there are small deformations. The position of point $\mathrm{P}$ due to the displacements $u, v, w, \theta_{y}$ and $\theta_{z}$ can be given by:

$$
\left[\begin{array}{c}
x \\
y \\
z
\end{array}\right]=\left[\begin{array}{c}
x_{0}+u-r \cos \varphi_{c} \sin \theta_{z}+r \sin \varphi_{c} \sin \theta_{y} \\
v+r \cos \varphi_{c} \cos \theta_{z} \\
w+r \sin \varphi_{c} \cos \theta_{y}
\end{array}\right] .
$$

By differentiating Eq. (4) with respect to time yields the velocities of point $P$.

$$
\left\{\begin{array}{l}
\dot{x}=\dot{u}+\omega r \theta_{z} \sin \varphi_{c}+\omega r \theta_{y} \cos \varphi_{c}-r \dot{\theta}_{z} \cos \varphi_{c}+r \dot{\theta}_{y} \sin \varphi_{c} \\
\dot{y}=\dot{v}-\omega r \sin \varphi_{c}-r \theta_{z} \dot{\theta}_{z} \cos \varphi_{c} \\
\dot{z}=\dot{w}+\omega r \cos \varphi_{c}-r_{z} \theta_{y} \dot{\theta}_{y} \sin \varphi_{c} .
\end{array}\right.
$$

The energy of the whole disk can be expressed as:

$$
\begin{aligned}
T= & \int_{b}^{a} \int_{0}^{2 \pi} t \rho r\left(\dot{x}^{2}+\dot{y}^{2}+\dot{z}^{2}\right) / 2 d r d \phi \\
& =J_{D} \omega^{2} / 2+m_{D}\left(\dot{u}^{2}+\dot{v}^{2}+\dot{w}^{2}\right) / 2 \\
& +I_{D}\left(\dot{\theta}_{y}^{2}+\dot{\theta}_{z}^{2}\right) / 2+\omega J_{D}\left(\dot{\theta}_{y} \theta_{z}-\theta_{y} \dot{\theta}_{z}\right) / 2
\end{aligned}
$$




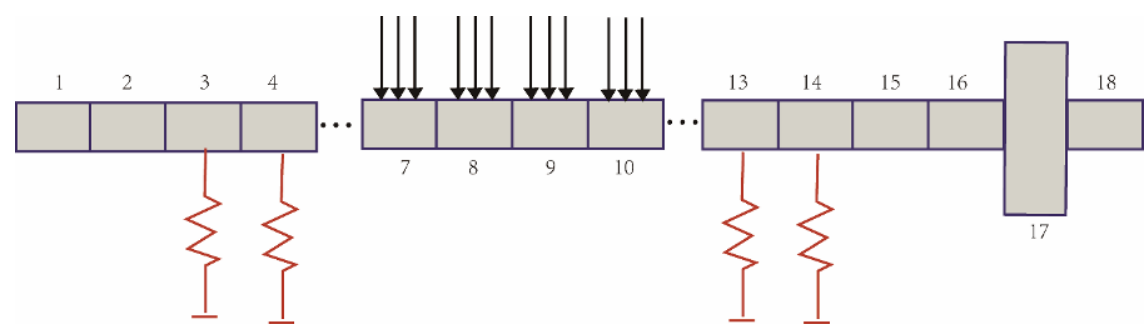

Fig. 8. FE model of the crankshaft-bearing system.

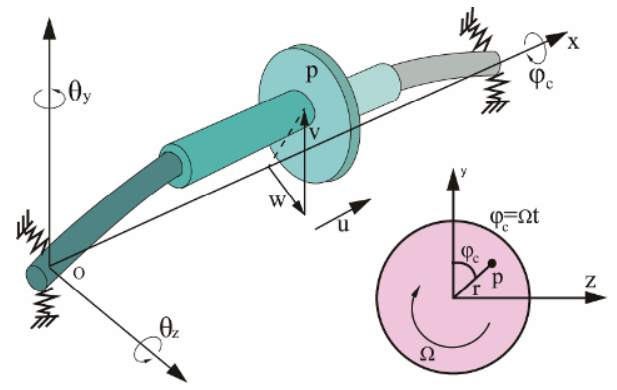

Fig. 9. Rigid disk element.

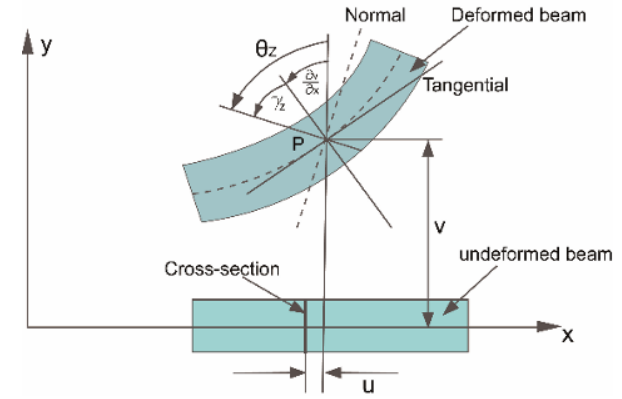

Fig. 10. Beam model of elastic shaft section.

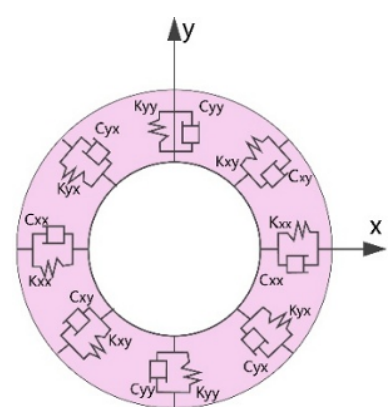

Fig. 11. Model of bearing. where $m_{D}=\rho \pi d_{1}^{2} t / 4, I_{D}=m_{D} d_{1}^{2} / 16, J_{D}=m_{D} d_{1}^{2} / 8$.

The differential equation of rigid disk based on the Lagrange equation can be expressed as:

$$
\left[M^{d}\right]\{\ddot{q}\}-\omega\left[G^{d}\right]\{\dot{q}\}=\left\{F^{d}\right\}
$$

where

$$
\begin{aligned}
& \left\{F^{d}\right\}=\left[m_{D} e \omega^{2} \cos \omega t\right. \\
& \{q\}=\left[\begin{array}{lllllll}
u & v & w & \theta_{y} & \theta_{z}
\end{array}\right]^{T},
\end{aligned}
$$

$$
\begin{aligned}
{\left[M^{d}\right] } & =\left[\begin{array}{ccccc}
m_{D} & 0 & 0 & 0 & 0 \\
0 & m_{D} & 0 & 0 & 0 \\
0 & 0 & m_{D} & 0 & 0 \\
0 & 0 & 0 & I_{D} & 0 \\
0 & 0 & 0 & 0 & I_{D}
\end{array}\right], \\
{\left[G^{d}\right] } & =\left[\begin{array}{ccccc}
0 & 0 & 0 & 0 & 0 \\
0 & 0 & 0 & 0 & 0 \\
0 & 0 & 0 & 0 & 0 \\
0 & 0 & 0 & 0 & -J_{D} \\
0 & 0 & 0 & J_{D} & 0
\end{array}\right]
\end{aligned}
$$

The Timoshenko beam is introduced to model the crank shaft with a pulley system (Fig. 10). The rotational angle of the cross section for the beam in the X-Y and X-Z plane can be expressed as:

$$
\left\{\begin{array}{l}
\theta_{z}=\gamma_{z}+\partial v / \partial x \\
\theta_{y}=\gamma_{y}-\partial w / \partial x
\end{array}\right.
$$

It is assumed that the cross section of beam keeps the same plane after deformation. The deformed and undeformed beam model of elastic shaft section is shown in Fig. 10 and the displacement of point $\mathrm{P}$ can be calculated as:

$$
\left\{\begin{array}{l}
u(x, y, z, t)=u(x, t)+\theta_{y} z-\theta_{z} y \\
v(x, y, z, t)=v(x, t) \\
w(x, y, z, t)=w(x, t)
\end{array}\right.
$$

When the second order strains are considered, the stains at point $\mathrm{P}$ can be given by:

$$
\left\{\begin{aligned}
\gamma_{y x}= & \partial v / \partial x+\partial u / \partial y=-\gamma_{z} \\
\gamma_{z x}= & \partial w / \partial x+\partial u / \partial z=\gamma_{y} \\
\varepsilon_{x x}= & \partial u / \partial x+z \partial \theta_{y} / \partial x-y \partial \theta_{z} / \partial x \\
& +(\partial v / \partial x)^{2} / 2+(\partial w / \partial x)^{2} / 2 .
\end{aligned}\right.
$$

The potential energy of the beam can be expressed as:

$$
\begin{aligned}
V= & \int \frac{1}{2} E_{s} \varepsilon_{x x}^{2} d V+\int \frac{1}{2} k_{s} A_{s} G_{s} \gamma_{y x}^{2} d V+\int \frac{1}{2} k_{s} A_{s} G_{s} \gamma_{z x}^{2} d V \\
= & \int_{0}^{L} \frac{1}{2} E_{s} A_{s}\left(\frac{\partial u}{\partial x}\right)^{2} d x+\int_{0}^{L} \frac{1}{2} k_{s} A_{s} G_{s}\left[\left(\theta_{y}+\frac{\partial w}{\partial x}\right)^{2}\right. \\
& \left.+\left(\theta_{z}-\frac{\partial v}{\partial x}\right)\right]^{2} d x+\int_{0}^{L} \frac{1}{2} E_{s} A_{s}\left[\left(\frac{1}{2}\left(\frac{\partial v}{\partial x}\right)^{2}\right)^{2}+\left(\frac{1}{2}\left(\frac{\partial w}{\partial x}\right)^{2}\right)^{2}\right] d x \\
& +\int_{0}^{L} \frac{1}{2} E_{s} I_{s}\left[\left(\frac{\partial \theta_{y}}{\partial x}\right)^{2}+\left(\frac{\partial \theta_{z}}{\partial x}\right)^{2}\right] d x
\end{aligned}
$$

The work done by the external force can be given by: 


$$
\begin{aligned}
W= & \int_{0}^{L}\left(q_{x} u+q_{y} v+q_{z} w+M_{y} \theta_{y}+M_{z} \theta_{z}\right) d x \\
& +\int_{0}^{L} \frac{1}{2} \omega^{2} v^{2} \rho A d x+\int_{0}^{L} \frac{1}{2} \omega^{2} w^{2} \rho A d x
\end{aligned}
$$

Applying the Hamilton's principle to the beam yields:

$$
\delta I=\delta \int_{t_{1}}^{t_{2}}(T-V+W) d t=0
$$

By solving Eq. (13), the following equations of motion for the beam can be expressed as follows:

$$
\begin{aligned}
& \rho A \frac{d^{2} u}{d t^{2}}-E A \frac{d^{2} u}{d x^{2}}-q_{x}=0 \\
& \rho A \frac{d^{2} v}{d t^{2}}-\frac{\partial\left[k_{s} A G\left(\frac{\partial v}{\partial x}-\theta_{z}\right)-P \frac{\partial v}{\partial x}\right]}{\partial x}-q_{y}-\omega^{2} \rho A v=0 \\
& \rho A \frac{d^{2} w}{d t^{2}}-\frac{\partial\left[k_{s} A G\left(\frac{\partial w}{\partial x}-\theta_{y}\right)-P \frac{\partial w}{\partial x}\right]}{\partial x}-q_{z}-\omega^{2} \rho A w=0 \\
& \rho I \frac{d^{2} \theta_{y}}{d t^{2}}+\omega \rho J \frac{d \theta_{z}}{d t}-E I \frac{d^{2} \theta_{y}}{d x^{2}}+k_{s} A G\left(\frac{\partial w}{\partial x}+\theta_{y}\right)-m_{y}=0 \\
& \rho I \frac{d^{2} \theta_{z}}{d t^{2}}-\omega \rho J \frac{d \theta_{y}}{d t}-E I \frac{d^{2} \theta_{z}}{d x^{2}}+k_{s} A G\left(\frac{\partial v}{\partial x}-\theta_{z}\right)-m_{z}=0 .
\end{aligned}
$$

The differential equations of the beam using the FEM can be described in matrix form:

$$
\left[M^{b}\right]\{\ddot{q}\}-\omega\left[G^{b}\right]\{\dot{q}\}+\left(\left[K^{b}\right]+\left[K^{b}\right]_{p}-\omega^{2}\left[M^{b}\right]_{C}\right)\{q\}=\left\{F^{b}\right\}
$$

where

$$
[M]_{T}=\frac{\rho A L}{420(1+\Phi)^{2}}\left[\begin{array}{ccccccccccc}
m_{a 1} & & & & & & & & & \\
0 & m_{1} & & & & S & & & & \\
0 & 0 & m_{1} & & & & Y & & & \\
0 & 0 & -m_{2} & m_{5} & & & & M & & \\
0 & m_{2} & 0 & 0 & m_{5} & & & & & \\
m_{a 2} & 0 & 0 & 0 & 0 & m_{a 1} & & & & \\
0 & m_{3} & 0 & 0 & -m_{4} & 0 & m_{1} & & & \\
0 & 0 & m_{3} & m_{4} & 0 & 0 & 0 & m_{1} & & \\
0 & 0 & -m_{4} & m_{6} & 0 & 0 & 0 & m_{2} & m_{5} & \\
0 & m_{4} & 0 & 0 & m_{6} & 0 & -m_{2} & 0 & 0 & m_{5}
\end{array}\right],
$$
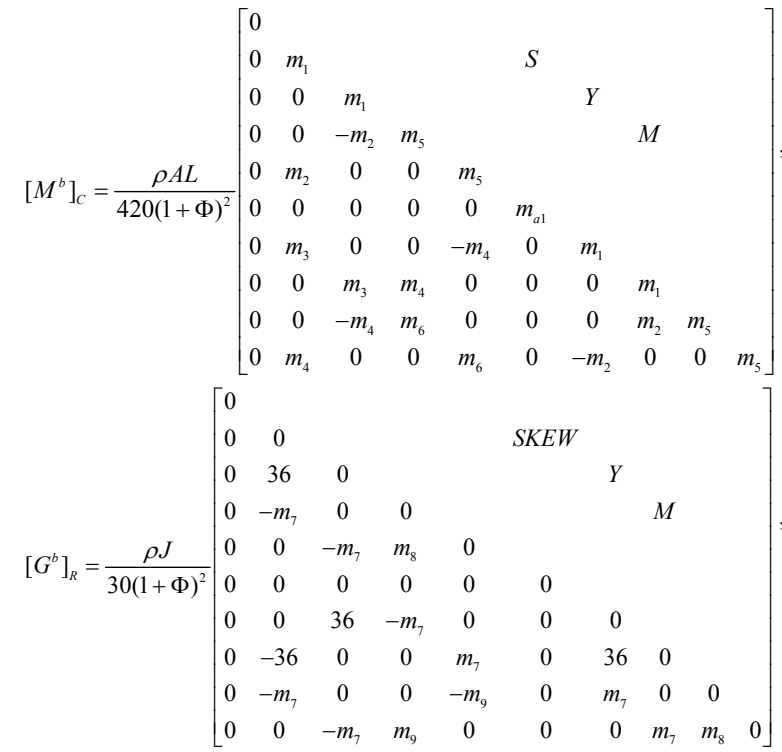

$$
\left[K^{b}\right]=\frac{E I}{(1+\Phi) L^{3}}\left[\begin{array}{ccccccccccc}
k_{1} & & & & & & & & & \\
0 & 12 & & & & S & & & & \\
0 & 0 & 12 & & & & Y & & & \\
0 & 0 & -6 L & k_{2} & & & & M & & \\
0 & 6 L & 0 & 0 & k_{2} & & & & & \\
-k_{1} & 0 & 0 & 0 & 0 & k_{1} & & & & \\
0 & -12 & 0 & 0 & -6 L & 0 & 12 & & & \\
0 & 0 & -12 & 6 L & 0 & 0 & 0 & 12 & & \\
0 & 0 & -6 L & k_{3} & 0 & 0 & 0 & 6 L & k_{2} \\
0 & 6 L & 0 & 0 & k_{3} & 0 & -6 L & 0 & 0 & k_{2}
\end{array}\right] \text {, }
$$

$\left[M^{b}\right]=[M]_{T}+[M]_{R}, m_{a 1}=140(1+\Phi)^{2}, m_{a 2}=70(1+\Phi)^{2}$, $m_{1}=156+294 \Phi+140 \Phi^{2}, m_{2}=\left(22+38.5 \Phi+17.5 \Phi^{2}\right) L$, $m_{3}=54+126 \Phi+70 \Phi^{2}, m_{4}=-\left(13+31.5 \Phi+17.5 \Phi^{2}\right) L$, $m_{5}=\left(4+7 \Phi+3.5 \Phi^{2}\right) L^{2}, m_{6}=-\left(3+7 \Phi+3.5 \Phi^{2}\right) L^{2}$, $m_{7}=(3-15 \Phi) L, m_{8}=\left(4+5 \Phi+10 \Phi^{2}\right) L^{2}$, $m_{9}=\left(-1-5 \Phi+5 \Phi^{2}\right) L, k_{1}=A(1+\Phi) L^{2} / I, k_{2}=(4+\Phi) L^{2}$, $k_{3}=(2-\Phi) L^{2}, k_{4}=36+60 \Phi+30 \Phi^{2}$, $k_{5}=\left(4+5 \Phi+2.5 \Phi^{2}\right) L^{2}, \Phi=12 E I /\left(k_{s} A G L^{2}\right)$, $\left\{F^{b}\right\}=\left[q_{x} L / 2, q_{y} L / 2-m_{z} /(1+\Phi), q_{z} L / 2+m_{y} /(1+\Phi)\right.$, $-q_{z} L^{2} / 12+\Phi m_{y} L / 2(1+\Phi), q_{y} L^{2} / 12+\Phi m_{z} L / 2(1+\Phi)$, $q_{x} L / 2, q_{y} L / 2+m_{z} /(1+\Phi), q_{z} L / 2-m_{y} /(1+\Phi)$, $\left.q_{z} L^{2} / 12+\Phi m_{y} L / 2(1+\Phi),-q_{y} L^{2} / 12+\Phi m_{z} L / 2(1+\Phi)\right]^{T}$ $k_{6}=-\left(1+5 \Phi+2.5 \Phi^{2}\right) L^{2}$.

Similarly, the model of the bearing is shown in Fig. 11 and the differential equations of bearing using the FEM can be 
Table 1. Parameters of the crank shaft system.

\begin{tabular}{|c|c|c|c|c|c|}
\hline No. of element (Crank shaft) & Length L (m) & Diameter D (m) & No. of element (Crank shaft) & Length L (m) & Diameter D (m) \\
\hline 1 & 0.1581 & 0.08 & 10 & 0.051 & 0.2 \\
\hline 2 & 0.013 & 0.16 & 11 & 0.09 & 0.18 \\
\hline 3 & 0.045 & 0.17 & 12 & 0.0425 & 0.16 \\
\hline 4 & 0.035 & 0.17 & 13 & 0.035 & 0.17 \\
\hline 5 & 0.0425 & 0.16 & 14 & 0.045 & 0.17 \\
\hline 6 & 0.09 & 0.18 & 15 & 0.013 & 0.16 \\
\hline 7 & 0.051 & 0.2 & 16 & 0.0606 & 0.14 \\
\hline 8 & 0.051 & 0.2 & 17 & 0.215 & 0.8 \\
\hline 9 & 0.051 & 0.2 & 18 & 0.1586 & 0.105 \\
\hline Disk (Node) & Mass (kg) & \multicolumn{2}{|c|}{ Polar moment of inertia $J_{p}\left(\mathrm{~kg}^{*} \mathrm{~m}^{2}\right)$} & \multicolumn{2}{|c|}{ Diameter of moment of inertia $J_{d}\left(\mathrm{~kg}^{*} \mathrm{~m}^{2}\right)$} \\
\hline 17 & 512 & \multicolumn{2}{|r|}{45.83} & \multicolumn{2}{|c|}{24.33} \\
\hline Bearing (Node) & $\mathrm{k}_{\mathrm{xx}}(\mathrm{N} / \mathrm{m})$ & $\mathrm{k}_{\mathrm{xy}}\left(\mathrm{k}_{\mathrm{yx}}\right)(\mathrm{N} / \mathrm{m})$ & $\mathrm{k}_{\mathrm{yy}}(\mathrm{N} / \mathrm{m})$ & $\mathrm{c}_{\mathrm{xx}}\left(\mathrm{c}_{\mathrm{yy}}\right)$ & $c_{x y}\left(c_{y x}\right)$ \\
\hline $3,4,13,14$ & $5 \times 10^{7}$ & 0 & $5 \times 10^{7}$ & 0 & 0 \\
\hline
\end{tabular}

given by:

$$
M_{b} \ddot{u}_{b}+C_{b 1} \dot{u}_{b}+K_{b 1} u_{b}=-C_{b 2}\left(\dot{u}_{b}-\dot{u}_{s}\right)-K_{b 2}\left(u_{b}-u_{s}\right)
$$

where

$$
\begin{aligned}
& M_{b}=\left[\begin{array}{cc}
M_{b y} & 0 \\
0 & M_{b z}
\end{array}\right], C_{b 1}=\left[\begin{array}{ll}
c_{b y y} & c_{b y z} \\
c_{b z y} & c_{b z z}
\end{array}\right], C_{b 2}=\left[\begin{array}{ll}
c_{y y} & c_{y z} \\
c_{z y} & c_{z z}
\end{array}\right], \\
& K_{b 1}=\left[\begin{array}{ll}
k_{b y y} & k_{b y z} \\
k_{b z y} & k_{b z z}
\end{array}\right], K_{b 2}=\left[\begin{array}{ll}
k_{y y} & k_{y z} \\
k_{z y} & k_{z z}
\end{array}\right], \begin{array}{l}
u_{b}=\left[v_{b}, w_{b}\right]^{T} \\
u_{s}=\left[v_{j}, w_{j}\right]^{T} .
\end{array}
\end{aligned}
$$

By combining Eqs. (7), (15) and (16) of the rigid disk, beam and bearings, the general nonlinear dynamic equations of the crankshaft-bearing system for MLUPPS can be expressed as:

$$
[M]\{\ddot{x}\}+[C]\{\dot{x}\}+[K]\{x\}=\{F(t)\}
$$

where

$$
\begin{aligned}
& {[M]=\left[M^{b}\right]+\left[M^{d}\right],[C]=\left[G^{b}\right]+\left[G^{d}\right]+\left[C^{s}\right],} \\
& {[K]=\left[K^{b}\right]+\left[K^{b}\right]_{p}+\left[K_{b 2}\right]-\omega^{2}\left[M^{b}\right]_{C},\{F(t)\}=\left\{F^{b}\right\}+\left\{F^{d}\right\}}
\end{aligned}
$$

The simulation parameters of the crankshaft-bearing system are listed in Table 1. When the parameters in Table 1 and the force between crank shaft and linkage in Appendix A.2 are substituted into Eq. (17), the load spectrum of crankshaftbearing system from the improved model under piling condition is shown in Fig. 12.

Fig. 12 shows that under piling condition, the peak values of the load spectrum at point $\mathrm{B}$ in the $\mathrm{X}$ and $\mathrm{Y}$ directions are $1.54 \mathrm{kN}$ and $18.03 \mathrm{kN}$, respectively, and those at point $\mathrm{E}$ in the $\mathrm{X}$ and $\mathrm{Y}$ directions are $0.39 \mathrm{kN}$ and $17.21 \mathrm{kN}$, respectively. It is revealed that the load spectrum from the improved model is less than that from the traditional model, which may be

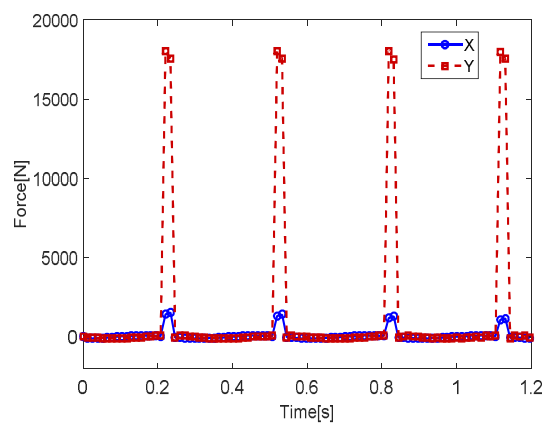

(a)

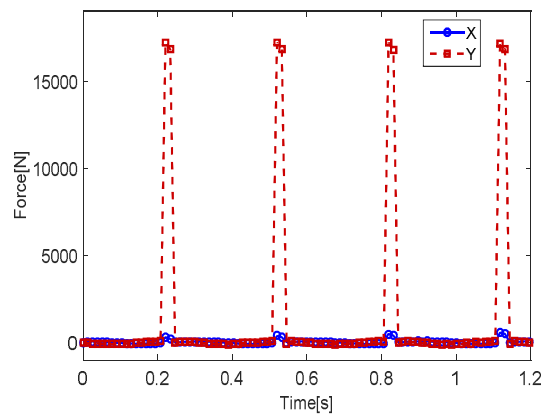

(b)

Fig. 12. Load spectrum of points in crank shaft system: (a) B; (b) E.

attributed to the existence of stiffness for bearing and flexibility of crank shaft.

\section{Thermal model of MLUPPS}

\subsection{FE model}

The thermal model of MLUPPS is developed under ANSYS software package (Fig. 13). SOLID70 has a 3-D thermal conduction capability and is chosen to simulate the temperature field distribution.

In order to balance the simulation precision and speed, the 
Table 2. Material properties of MLUPPS.

\begin{tabular}{|c|c|c|c|c|c|}
\hline Components & Press frame & Crank shaft & Bearing seat & Link & Slider \\
\hline Material & НT300 & $40 \mathrm{Cr}$ & 45 & QT600-3 & HT200 \\
\hline Density $\left(\mathrm{kg} / \mathrm{m}^{3}\right)$ & 7300 & 7870 & 7850 & 7200 & 7200 \\
\hline Modulus (N/m²) & $1.35 \times 10^{11}$ & $2.15 \times 10^{11}$ & $2.06 \times 10^{11}$ & $1.69 \times 10^{11}$ & $1.05 \times 10^{11}$ \\
\hline Poisson's ratio & 0.27 & 0.277 & 0.29 & 0.286 & 0.25 \\
\hline Heat conductivity coefficient $(\mathrm{W} /(\mathrm{m} \cdot \mathrm{K}))$ & 46.05 & 43.96 & 41 & 36 & 50.24 \\
\hline Specific heat capacity $(\mathrm{J} /(\mathrm{kg} \cdot \mathrm{K}))$ & 544.28 & 552.66 & 553 & 439.6 & 502.42 \\
\hline Coefficient of thermal expansion $(1 / \mathrm{K})$ & $1.05 \times 10^{-5}$ & $1.2 \times 10^{-5}$ & $1.25 \times 10^{-5}$ & $1.09 \times 10^{-5}$ & $1.05 \times 10^{-5}$ \\
\hline
\end{tabular}

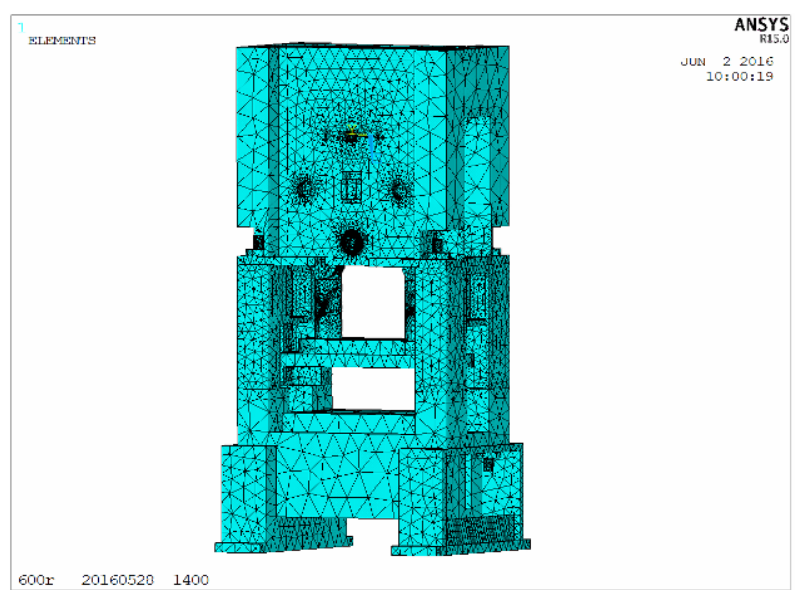

Fig. 13. Thermal model of MLUPPS.

following assumptions are made: (1) Bearings are considered to be a hollow cylinder with non-uniform heat generation rate. (2) The effect of the thermal contact resistances among components of press frame is neglected. (3) The radiation term can be neglected due to a lower temperature rise.

The material properties of MLUPPS are listed in Table 2 and the FE model of the whole MLUPPS has a total of 2423751 solid elements.

To simulate the contact characteristics between the joints, the contact elements CONTA174 and TARGE170 are selected. The effect of the thermal contact resistances on the contact surfaces between the outer rings and the bearing support, and the inner rings and the shaft neck is considered. The thermal contact conductance coefficient of real constant for each contact element of the joints is defined as follows.

\subsection{Thermal contact resistance}

The thermal contact resistance of joint is given by [30]:

$$
R=L_{g} /\left[A\left(A_{r}^{*} k+\left(1-A_{r}^{*}\right) k_{f}\right)\right]
$$

where $k=2 k_{1} k_{2} /\left(k_{1}+k_{2}\right)$.

The void space thickness $L_{g}$ between two contact surfaces of the joint based on the fractal theory can be expressed as [9]:

$$
L_{g}=2\left[z-\psi^{(D-2)(D-2) / 4} G^{D-1}\left(\frac{4-2 D}{D}\right)^{(2-D) / 2}\left(A_{r}^{*}\right)^{(2-D) / 2} L_{u}^{2-D}\right] .
$$

If the largest contact area $a_{L}$ is smaller than the critical area $a_{c}$, there exists only the plastic deformation and the dimensionless fractional contact area of the fractal domain $A_{r}^{*}$ can be calculated as:

$$
A_{r}^{*}=P / H \text {. }
$$

When the largest contact area $a_{L}$ is larger than the critical area $a_{c}$, both elastic and plastic contact exist. It is assumed that the small term of contact can be neglected. Integrating the elastic and plastic forces of the joint yields [31]:

$$
A_{r}^{*}=\left\{\begin{array}{cc}
\left(\frac{3 \sqrt{2 \pi}}{4}\right)^{2 /(3-D)}\left(\frac{L_{u}}{G}\right)^{(2 D-2) /(3-D)} g_{4}(D)\left(\frac{P}{E_{e}}\right)^{2 /(3-D)} & D<1.5 \\
{\left[g_{3}(D)\right]^{-2 D}\left(\frac{P}{E_{e}}\right)^{2 / D}\left\{\frac{4}{3 \sqrt{2 \pi}}\left(\frac{G}{L_{u}}\right)^{D-1}\left[-g_{1}(D)\right]\left(a_{c}^{*}\right)^{(3-2 D) / 2}+\frac{H}{E} g_{2}(D)\left(a_{c}^{*}\right)^{(2-D) / 2}\right\}^{-2 / D}} & D>1.5
\end{array}\right.
$$

where

$$
\begin{aligned}
& a_{c}=G^{2} /(H / 2 E)^{2 /(D-1)}, E_{e}=\left[\left(1-v_{1}^{2}\right) / E_{1}+\left(1-v_{2}^{2}\right) / E_{2}\right]^{-1}, \\
& g_{1}(D)=[(2-D) / D]^{D / 2} D /(3-2 D), \\
& g_{2}(D)=[D /(2-D)]^{(2-D) / 2}, \\
& g_{3}(D)=2^{D / 2} \psi^{\left(4-4 D+D^{2}\right) / 4}, \\
& g_{4}(D)=\left[g_{1}(D) g_{3}(D) \psi^{(D-2)(3-2 D) / 4}\right]^{2 /(D-3)}[D /(4-2 D)]^{(3-2 D) /(3-D)} .
\end{aligned}
$$

The calculation results of thermal contact resistances at different contact locations of press system are listed in Table 3 .

\subsection{Heat generation and heat transfer}

\subsubsection{Heat generation power}

The heat generation power of the angular contact ball bearing caused by friction between the ball and groove [32] is given by:

$$
H_{f}=1.047 \times 10^{-4} n T \text {. }
$$

The total friction torque of bearing, composed of three parts, 
Table 3. Thermal contact resistances at different contact locations of press system.

\begin{tabular}{c|c|c|c|c|c}
\hline Location of contact & $\begin{array}{c}\text { Rolling bearing and } \\
\text { bearing seats }\end{array}$ & $\begin{array}{c}\text { Rolling bearings and } \\
\text { crank shaft }\end{array}$ & $\begin{array}{c}\text { Main slider and } \\
\text { guide way }\end{array}$ & $\begin{array}{c}\text { Balance slider and } \\
\text { press frame }\end{array}$ & $\begin{array}{c}\text { Linkages and } \\
\text { sliding bearings }\end{array}$ \\
\hline $\begin{array}{c}\text { Thermal contact } \\
\text { resistances }\left(\mathrm{m}^{2} \mathrm{k} / \mathrm{w}\right)\end{array}$ & $5.88 \times 10^{-6}$ & $6.01 \times 10^{-6}$ & $6.55 \times 10^{-6}$ & $6.87 \times 10^{-6}$ \\
\hline
\end{tabular}

Table 4. Relationship of $X_{s}$ and $Y_{s}$ with respect to contact angle.

\begin{tabular}{|c|c|c|c|c|c|c|}
\hline Contact angle & $15^{0}$ & $20^{\circ}$ & $25^{0}$ & $30^{\circ}$ & $35^{0}$ & $40^{\circ}$ \\
\hline$X_{s}$ & 0.5 & 0.5 & 0.5 & 0.5 & 0.5 & 0.5 \\
\hline$Y_{s}$ & 0.47 & 0.42 & 0.38 & 0.33 & 0.29 & 0.26 \\
\hline
\end{tabular}

Table 5. Heat generation power at different joints.

\begin{tabular}{|c|c|c|c|c|c|c|}
\hline Temperature & $20^{\circ} \mathrm{C}$ & $30^{\circ} \mathrm{C}$ & $40^{\circ} \mathrm{C}$ & $50^{\circ} \mathrm{C}$ & $60^{\circ} \mathrm{C}$ & $70^{\circ} \mathrm{C}$ \\
\hline Locations of joints & \multicolumn{6}{|c|}{ Heat generation power $(\mathrm{W})$} \\
\hline Between upper beam 1 and crank shaft 2 & 2023.66 & 1647.07 & 1273.22 & 1028.90 & 850.11 & 727.83 \\
\hline Between crank shaft 2 and main linkage 3 & 927 & 697 & 494 & 379 & 304 & 258 \\
\hline Among main linkage 3 , slider 4 and swing link 5 & 485.7186 & 373.725 & 275.7306 & 219.7338 & 183.3358 & 160.937 \\
\hline Between swing link 5 and supporting link 6 & 490.7624 & 378.7686 & 280.7742 & 224.7774 & 188.3794 & 165.9808 \\
\hline Between supporting link 6 and upper beam 1 & 222.6266 & 179.5456 & 141.8498 & 120.3094 & 106.308 & 97.6918 \\
\hline Between swing link 5 and linkage 7 & 215.1616 & 172.0806 & 134.3848 & 112.8442 & 98.843 & 90.2268 \\
\hline Among linkage 7 , toggle link 8 and linkage 9 & 480.4978 & 368.5042 & 270.5096 & 214.5128 & 178.115 & 155.7162 \\
\hline Between connecting rod 9 and slider 10 & 710 & 565 & 437 & 365 & 318 & 288 \\
\hline Between toggle link 8 and upper beam 1 & 898.0688 & 667.1818 & 465.1556 & 349.712 & 274.6738 & 228.4964 \\
\hline Between toggle link 8 and auxiliary linkage 11 & 940.192 & 751.8956 & 564.9734 & 442.8144 & 353.4174 & 292.2802 \\
\hline Between linkage 11 and balance slider 12 & 303.9306 & 243.07 & 182.6536 & 143.1698 & 114.2752 & 94.5146 \\
\hline Between slider 10 and upper beam 1 & \multicolumn{6}{|c|}{362.23} \\
\hline Between balance slider 12 and upper beam 1 & \multicolumn{6}{|c|}{276.8344} \\
\hline Between slider 4 and upper beam 1 & \multicolumn{6}{|c|}{158.2957} \\
\hline
\end{tabular}

can be expressed as:

$$
T=T_{1}+T_{2}+T_{3} .
$$

Torque $M_{1}$ of the ball bearing is expressed as:

$$
T_{1}=f_{1} P_{1} d_{m}
$$

where $f_{1}=0.001\left(P_{0} / c_{0}\right)^{0.33}, P_{1}=1.4 F_{a}-0.1 F_{r}$, $P_{0}=X_{s} F_{r}+X_{Y} F_{a}$.

The parameters $X_{s}$ and $Y_{s}$ vary with respect to the change of contact angle for single row angular contact ball bearings and the relationship between parameters $X_{s}, Y_{s}$ and contact angle is shown in Table 4.

Torque $M_{2}$ of the ball bearing from the viscous friction is empirically given by:

$$
T_{2}=\left\{\begin{array}{cc}
10^{-7} f_{0}\left(v_{0} n\right)^{2 / 3} d_{m}^{3} & v_{0} n \geq 2000 \\
160 \times 10^{-7} f_{0} d_{m}^{3} & v_{0} n<2000
\end{array}\right.
$$

The spin torque $M_{3}$ of the bearing can be calculated as [31]:

$$
T_{3}=3 \mu Q a \xi / 8
$$

Similarly, heat generation power of the guide way is calculated by [33]:

$$
H_{g}=\mu F_{n} V
$$

The computation results of heat generation power for press system are listed in Table 5 .

\subsubsection{Heat transfer coefficient}

The heat transfer coefficient of convection for rotating surface is given by $[2,34]$ :

$$
h=N_{u} k_{f l u i d} / d .
$$

The Nusselt number can be given by [35]:

$$
N_{u}=0.133 R_{e}^{2 / 3} P_{r}^{1 / 3}
$$

where $R_{e}=u_{\text {fluid }} d / v_{\text {fluid }}, \quad P_{r}=\left(c_{\text {fluid }} \mu_{\text {fluid }}\right) / k_{\text {fluid }}$. Eq. (29) is 
Table 6. Parameters of convection under infinite space.

\begin{tabular}{|c|c|c|c|c|c|}
\hline \multicolumn{2}{|c|}{ Surface shape and orientation } & Flow state & $c$ & $n$ & Scope of $G_{r} \cdot P_{r}$ \\
\hline \multirow{2}{*}{\multicolumn{2}{|c|}{ Vertical flat wall }} & Laminar & 0.59 & $1 / 4$ & $10^{4} \leq G_{r} \cdot P_{r} \leq 10^{9}$ \\
\hline & & Turbulence & 0.13 & $1 / 3$ & $10^{9} \leq G_{r} \cdot P_{r} \leq 10^{12}$ \\
\hline \multirow{3}{*}{ Horizontal flat wall } & \multirow{2}{*}{$\begin{array}{l}\text { Hot plate in upper surface or cold plate in } \\
\text { lower surface }\end{array}$} & Laminar & 0.54 & $1 / 4$ & $10^{5} \leq G_{r} \cdot P_{r} \leq 2 \times 10^{7}$ \\
\hline & & Turbulence & 0.14 & $1 / 3$ & $2 \times 10^{7} \leq G_{r} \cdot P_{r} \leq 3 \times 10^{10}$ \\
\hline & $\begin{array}{l}\text { Hot plate in lower surface or cold plate in } \\
\text { upper surface }\end{array}$ & Laminar & 0.27 & $1 / 4$ & $3 \times 10^{5} \leq G_{r} \cdot P_{r} \leq 3 \times 10^{10}$ \\
\hline
\end{tabular}

Table 7. Physical properties of air.

\begin{tabular}{c|c|c}
\hline $\begin{array}{c}\text { Temperature } \\
\left({ }^{\circ} \mathrm{C}\right)\end{array}$ & $\begin{array}{c}\text { Heat conductivity } \\
\text { coefficient } \alpha(\mathrm{W} /(\mathrm{m} \cdot \mathrm{K}))\end{array}$ & $\begin{array}{c}\text { Kinematic viscosity } \\
v_{\text {fuid }}\left(\mathrm{mm}^{2} / \mathrm{s}\right)\end{array}$ \\
\hline 20 & $2.59 \times 10^{-2}$ & $18.1 \times 10^{-6}$ \\
\hline 30 & $2.67 \times 10^{-2}$ & $18.6 \times 10^{-6}$ \\
\hline 40 & $2.73 \times 10^{-2}$ & $19.1 \times 10^{-6}$ \\
\hline 50 & $2.83 \times 10^{-2}$ & $25.7 \times 10^{-6}$ \\
\hline 60 & $2.90 \times 10^{-2}$ & $27.2 \times 10^{-6}$ \\
\hline 70 & $2.96 \times 10^{-2}$ & $28.6 \times 10^{-6}$ \\
\hline
\end{tabular}

only valid for $R_{e}<4.3 \times 10^{5}, 0.7<P_{r}<670$. For the air under the normal temperature, $P_{r}=0.707$.

When the surface temperature of MLUPPS is higher than that of air surrounded, the density of air near press system decreases as a result of heat and the air rises. Then the cold air in the vicinity of machine flows to press system, which forms a cycle between press surface and fluid due to natural convection. When the press is in the factory, the convection condition of press frame structure is similar to that of the infinite space. The flow state of air includes laminar and turbulence flow and is determined by Gratchev and Prandtl number. The Nusselt number for horizontal or vertical flat wall can be calculated as:

$$
N_{u}=c\left(G_{r} \cdot P_{r}\right)^{n}
$$

The Gratchev number is expressed as:

$$
G_{r}=g \alpha \Delta t l^{3} / v_{\text {fluid }}^{2}
$$

The parameters of convection under infinite space are listed in Table 6 and $c, n$ can be obtained from Table 6 based on the product of Gratchev and Prandtl number. Heat conductivity coefficient and kinematic viscosity for air vary with the change of temperature and its relationship is shown in Table 7.

For free convection of surfaces in crank shaft system, $h=9.7 \mathrm{~W} /\left(\mathrm{m}^{2} \mathrm{~K}\right)$, and for free convection of surfaces on press frame structure, $h=5 \mathrm{~W} /\left(\mathrm{m}^{2} \mathrm{~K}\right)$.

\section{Results and discussion}

\subsection{Analysis of temperature change history}

The thermal analysis of MLUPPS is composed of the temperature change history of MLUPPS including temperature rise and the corresponding dimensional error due to thermal expansion between slider and work table at the position of BDP for MLUPPS. To validate the proposed thermal model of MLUPPS, temperature evolution of total eight points for the total press system are tested. Two points (Numbered $\mathrm{P}_{1}$ and $\mathrm{P}_{2}$ ) are located on the upper beam and crank shaft respectively, and six points (Numbered A, B, C, D, E and F) are located on the whole MLTM. Points A to F are located at the lower part of link 9, lower part of link 8, right part of upper beam, left part of crank shaft 2, guide way of slider 4, and upper part of link 8' respectively, as shown in Figs. 1 and 2. The traditional model of press system neglects the effect of bearing stiffness and flexibility of crank shaft on heat generation power, while the improved model of press system considers the effect of stiffness of bearing and flexibility of crank shaft on the heat generation power. The temperature evolution of two locations $\left(\mathrm{P}_{1}\right.$ and $\left.\mathrm{P}_{2}\right)$ at the upper beam and crank shaft predicted by both traditional and improved models under the input speed of $200 \mathrm{rpm}$ and piling force of $300 \mathrm{kN}$ as well as a room temperature of $20^{\circ} \mathrm{C}$ is shown in Fig. 14 .

Fig. 14 shows that the temperature of upper beam and crank shaft rises sharply within the first hour and then increases slowly after 1.5 hours and it will take more than 2.5 hours for the MLUPPS to reach the thermal equilibrium. The temperature rise of two locations at the upper beam and crank shaft are 7.80 and $15.19^{\circ} \mathrm{C}$. It is revealed that the temperature evolution with time that is predicted by the proposed thermal model agrees better with the measured data than by the traditional model. The temperature of upper beam and crank shaft for MLUPPS is overestimated by the traditional model due to neglecting heat generation caused by bearing stiffness and crank shaft flexibility.

In order to further validate the proposed thermal model of MLUPPS, temperature evolutions at six locations of the press system with the input speed of $200 \mathrm{rpm}$ under both no-load condition and piling force of $300 \mathrm{kN}$ are also simulated and compared with the measured data shown in Fig. 15. 


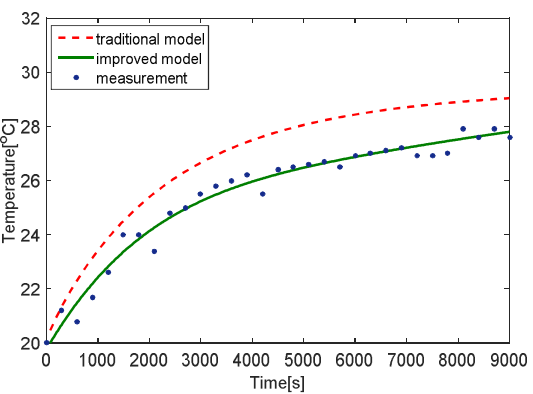

(a)

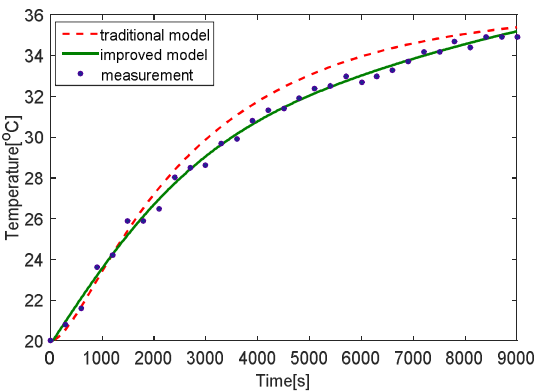

(b)

Fig. 14. Temperature change history of two locations at the upper beam and crank shaft: (a) P1; (b) P2.

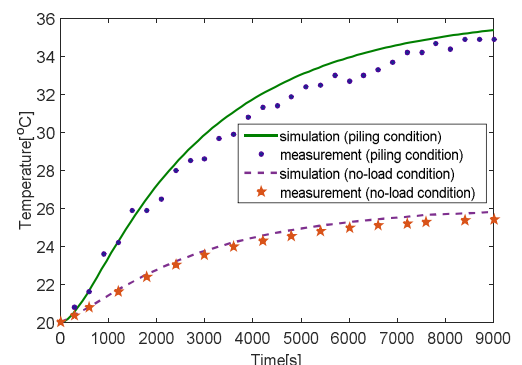

(a)

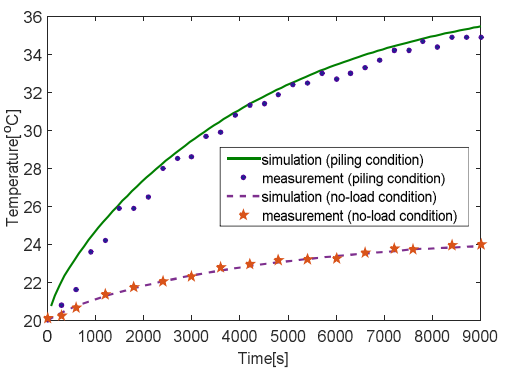

(d)

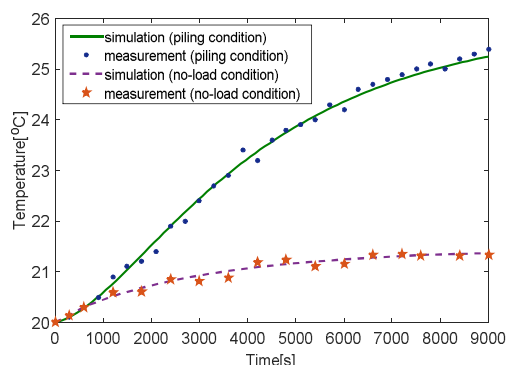

(b)

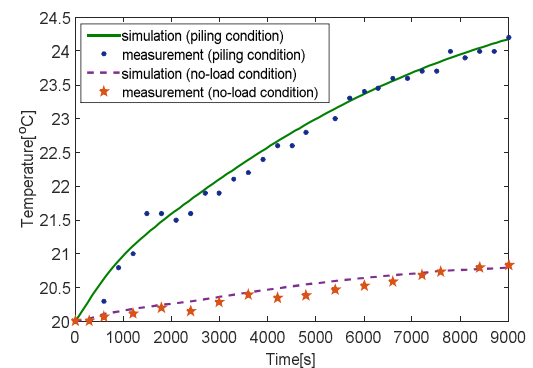

(e)

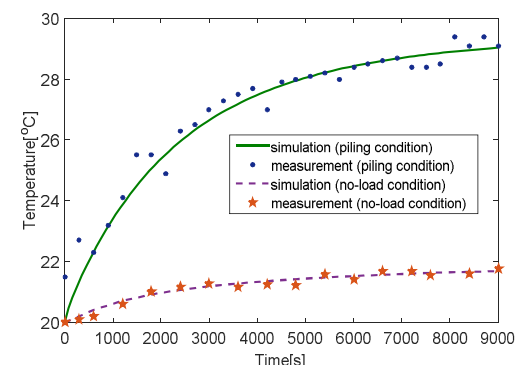

(c)

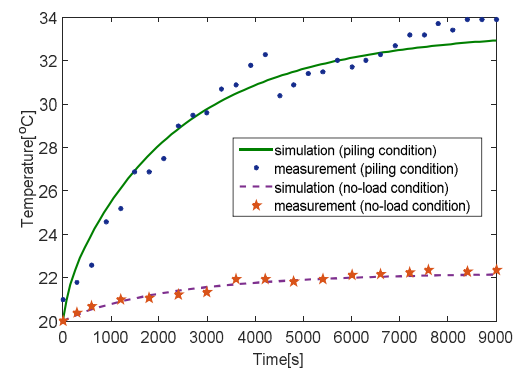

(f)

iig. 15. Temperature change history of different locations for MLUPPS: (a) A; (b) B; (c) C; (d) D; (e) E; (f) F.

Fig. 15 shows that the simulated temperature change history at six locations of the MLUPPS under both no-load and piling conditions from the proposed thermal model are consistent with the measured results. It is generally revealed that the temperature of the six locations increases significantly at the beginning stage, and reaches the steady value when the heat generation balances with the heat dissipation to the surroundings. The temperature rising time for press frame structure is much longer than that of the bearings. The temperature rises for the locations $\mathrm{A}$ to $\mathrm{F}$ under piling condition predicted by the proposed thermal model are 15.39, 5.25, 9.10, 15.48, 4.20 and $12.93{ }^{\circ} \mathrm{C}$, respectively, and those under no-load condition are $5.81,1.34,1.69,3.91,0.79$ and $2.16{ }^{\circ} \mathrm{C}$, respectively, which are well consistent with the measurement results.

\subsubsection{Effect of rotation speed on temperature rise}

The influence of rotation speeds of crank shaft on the temperature rise of six locations was investigated. In the simula-

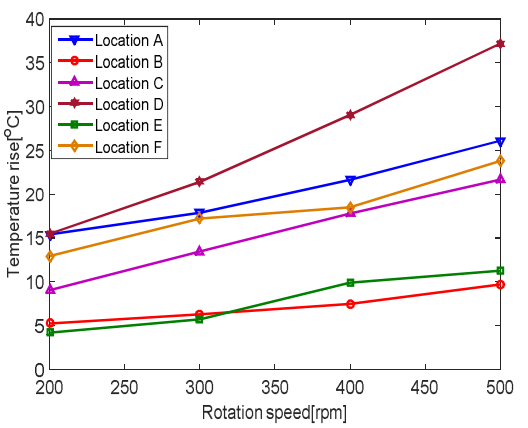

Fig. 16. Temperature rise of six locations for press system under different rotation speeds.

tion, when the piling force is $300 \mathrm{kN}$ and the stiffness of bearing is $5 \times 10^{8} \mathrm{~N} / \mathrm{m}$, the temperature rise on six locations of the press system at room temperature of $20{ }^{\circ} \mathrm{C}$ under different rotation speeds of the crank shaft are shown in Fig. 16. 


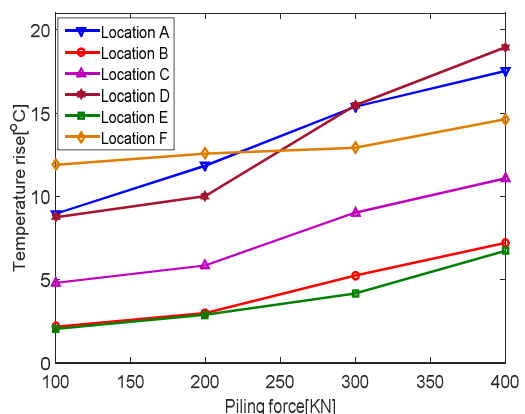

Fig. 17. Temperature rise of six locations for press system under different piling forces.

Fig. 16 shows that the temperature rise of six locations for MLUPPS increase with increments of the input speed of the crank shaft. When the crank shaft rotates at 200, 300, 400 and $500 \mathrm{rpm}$, the temperature rises of location $\mathrm{A}$ at the lower part of link 9 are $15.39,17.89,21.63$ and $26.09{ }^{\circ} \mathrm{C}$, respectively. Similarly, the temperature rises of location B at the lower part of link 8 for multi-link mechanism are 5.25, 6.3, 7.46 and $9.69{ }^{\circ} \mathrm{C}$. The temperature rises of location $\mathrm{C}$ at the upper beam are $9.04,13.46,17.8$ and $21.65{ }^{\circ} \mathrm{C}$. For the location $\mathrm{D}$ at the crank shaft, the temperature rises are 15.48, 21.4, 29.05 and $37.19^{\circ} \mathrm{C}$. For the location $\mathrm{E}$ at the guide rail, the temperature rises are 4.18, 5.72, 9.89 and $11.27{ }^{\circ} \mathrm{C}$. For the location $\mathrm{F}$ at the upper part of the link 8 ', the temperature rises are 12.94, $17.23,18.49$ and $23.77{ }^{\circ} \mathrm{C}$. It is revealed that the maximum temperature rise of MLUPPS occurs at the crank shaft, which results from the accumulated heat generation at the bearing of crank shaft system. The temperatures of $\mathrm{A}$ and $\mathrm{D}$ are higher than those of $\mathrm{B}$ and $\mathrm{E}$, the reason of which is that the heat generation power of bearing on the crank shaft and joint between link 9 and slider 10 is larger than that of joint between link 8 and 7, guide way. With the increase of rotational speed, the heat generation power of heat sources near the selected points rises, which causes the corresponding temperature rise.

\subsubsection{Effect of piling force on temperature rise}

The influence of piling force on the temperature rise of six locations for the press system was investigated. In the simulation, when the input speed of the crank shaft is $200 \mathrm{rpm}$ and the stiffness of bearing is $5 \times 10^{8} \mathrm{~N} / \mathrm{m}$, the temperature rise for six locations of the press system at the room temperature of $20^{\circ} \mathrm{C}$ under different piling forces are shown in Fig. 17.

Fig. 17 shows that the temperature rise of six locations for MLUPPS boosts with the increase of piling load. When the press system operates at $100,200,300$ and $400 \mathrm{kN}$, the temperature rises of location A at the lower part of link 9 are 8.97, $11.85,15.39$ and $17.54{ }^{\circ} \mathrm{C}$, respectively. Similarly, the temperature rises of location $\mathrm{B}$ at the lower part of link 8 for multi-link mechanism are $2.19,3.02,5.25$ and $7.21{ }^{\circ} \mathrm{C}$. The temperature rises of location $\mathrm{C}$ at the upper beam are 4.82 , 5.87, 9.04 and $11.09^{\circ} \mathrm{C}$. For the location D at the crank shaft, the temperature rises are $8.76,10.03,15.48$ and $18.95{ }^{\circ} \mathrm{C}$,

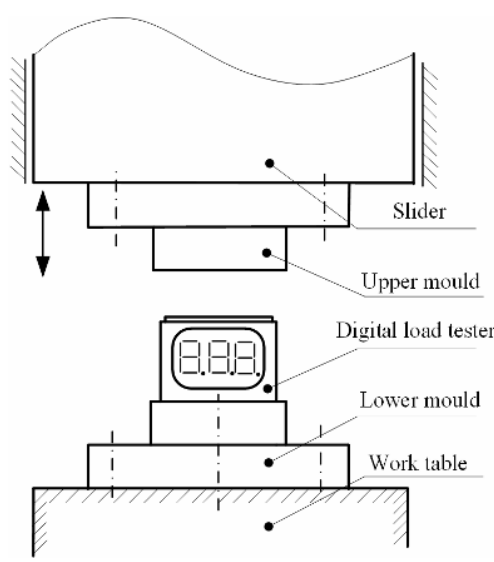

Fig. 18. A schematic diagram showing the measurement for piling force.

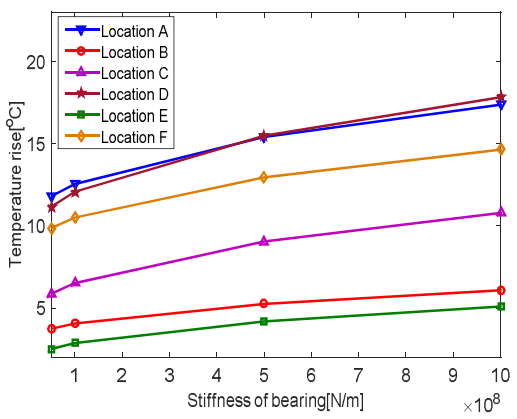

Fig. 19. History on temperature change of six locations for press system under different stiffness of bearing.

respectively. For the location $\mathrm{E}$ at the guide rail, the temperature rises are $2.06,2.91,4.18$ and $6.74{ }^{\circ} \mathrm{C}$, respectively. For the location $\mathrm{F}$ at the upper part of the link 8 ', the temperature rises are $11.91,12.59,12.94$ and $14.64{ }^{\circ} \mathrm{C}$. Similarly, the temperatures of $\mathrm{A}$ and $\mathrm{D}$ are higher than those of $\mathrm{B}$ and $\mathrm{E}$. With the increase of piling force, the heat generation power of heat sources near the selected points rises, which causes the corresponding temperature rise.

In practice, to change the piling force when the speed of crank shaft is constant, it is usually carried out by adjusting the height of the mold. However, the value of the corresponding piling force is unknown, which is measured by digital load tester that is fixed on the lower mold shown in Fig. 18. When the press system operates, the upper mold will contact with the digital load tester and the piling force is shown on the display of tester. It is necessary to lock the adjustment mechanism after obtaining the required working force based on the method of modifying the mold height.

\subsubsection{Effect of stiffness of bearing on temperature rise}

The influence of stiffness of bearing on temperature rise of six locations was investigated. In the simulation, when the rotation speed of the crank shaft is $200 \mathrm{rpm}$ and the piling force is $300 \mathrm{kN}$, the temperature rises for six locations of the press system at the room temperature of $20^{\circ} \mathrm{C}$ under different 


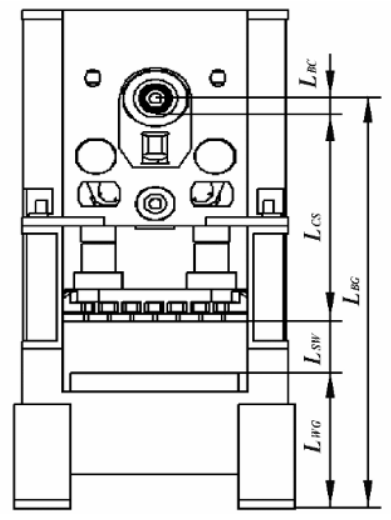

Fig. 20. Thermal dimension chain of the whole MLUPPS.

stiffness of bearing are shown in Fig. 19.

Fig. 19 shows that the temperature rises of six locations for MLUPPS increase with increments of stiffness of bearing. When the stiffness of bearing are $5 \times 10^{7}, 1 \times 10^{8}, 5 \times 10^{8}$ and $1 \times 10^{9} \mathrm{~N} / \mathrm{m}$, the temperature rises of location $A$ at the lower part of link 9 are $11.79,12.54,15.39$ and $17.37{ }^{\circ} \mathrm{C}$, respectively. The temperature rises of location $\mathrm{B}$ at the lower part of link 8 for multi-link mechanism are 3.74, 4.06, 5.25 and $6.08{ }^{\circ} \mathrm{C}$. The temperature rises of location $\mathrm{C}$ at the upper beam are $5.85,6.52,9.04$ and $10.79{ }^{\circ} \mathrm{C}$. For the location $\mathrm{D}$ at the crank shaft, the temperature rises are $11.15,12.07,15.48$ and $17.83{ }^{\circ} \mathrm{C}$. For the location $\mathrm{E}$ at the guide rail, the temperature rises are $2.51,2.86,4.18$ and $5.09{ }^{\circ} \mathrm{C}$. For the location $\mathrm{F}$ at the upper part of the link 8', the temperature rises are 9.85, $10.5,12.94$ and $14.64{ }^{\circ} \mathrm{C}$. The temperatures of $\mathrm{A}$ and $\mathrm{D}$ are also higher than those of $\mathrm{B}$ and $\mathrm{E}$. With the increase of bearing stiffness, the heat generation power of heat sources near the selected points rises, which causes the corresponding temperature rise.

\subsection{Thermal induced error analysis}

In order to analyze the thermal dimension error between slider and work table at the position of BDP as a result of thermal expansion, the thermal dimension chain of the whole MLUPPS is established (Fig. 20). Prior to the dynamic error analysis operation, the initial dimension chain for the whole MLUPPS can be given by:

$$
L_{S W 0}=L_{B G 0}-L_{W G 0}-L_{C S 0}-L_{B C 0}
$$

where $L_{S W 0}, L_{B G 0}, L_{W G 0}, L_{C S 0}$ and $L_{B C 0}$ represent the initial dimension between slider and work table, bearing seat center and ground, work table and ground, crank shaft center and slider, bearing seat center and crank shaft center, respectively.

When the MLUPPS operates under piling condition, each dimension in the chain changes with respect to time due to thermal deformation of each component. The thermal dimension chain of the whole MLUPPS at the position of BDP can be described as:

$$
L_{S W}(t)=L_{B G}(t)-L_{W G}(t)-L_{C S}(t)-L_{B C}(t)
$$

where $L_{S W}(t), L_{B G}(t), L_{W G}(t), L_{C S}(t)$ and $L_{B C}(t)$ represent the actual dimension between slider and work table, bearing seat center and ground, work table and ground, crank shaft center and slider, and bearing seat center and crank shaft center, respectively.

The thermal performance of press system is mainly determined by the relative dimensional precision between slider and work table at the position of BDP. Then, the dimensional chain of thermal error can be expressed as follows:

$$
E_{S W}(t)=E_{B G}(t)-E_{W G}(t)-E_{C S}(t)-E_{B C}(t)
$$

where

$$
\begin{aligned}
& E_{B G}(t)=L_{B G}(t)-L_{B G 0}, E_{W G}(t)=L_{W G}(t)-L_{W G 0}, \\
& E_{B S}(t)=L_{B S}(t)-L_{B S 0}, E_{B C}(t)=L_{B C}(t)-L_{B C 0} .
\end{aligned}
$$

The thermal displacement of MLUPPS in the vertical direction is shown in Fig. 21 and the dimensional error between slider and work table at the position of BDP as a result of the thermal expansion is shown in Fig. 22.

Fig. 21 shows the displacement of the upper beam and the crank shaft that contributes to the thermal dimension error of press system and the maximum displacement exists at the crank shaft system. The simulation results in Fig. 22 indicates that the thermal dimension error curves are composed of two parts. During the first hour after thermal simulation, the thermal dimension error between slider and work table at the position of BDP rises at a relatively rapid speed. As the volume of press frame structure is larger than that of components in mechanism, the temperature rise of crank shaft and linkages in the multi-link mechanism is more rapid than that of press frame structure during the initial stage. Then, the deformation of the crank shaft and linkages in mechanism is larger than that of press frame structure, which causes the thermal error of press system to increase. During the following period, the thermal dimension error between slider and work table at the position of BDP gradually decreases with a relatively slow speed. The reason for this phenomenon is likely contributed to the deformation of the crank shaft and linkages in mechanism reaches a balance, while the press frame structure deforms quickly as a result of continuous temperature rise. The maximum thermal dimension error between slider and work table at the position of BDP from both traditional and proposed models are $4.728 \mu \mathrm{m}$ and $4.258 \mu \mathrm{m}$, respectively. The balanced dimensional error due to thermal expansion are $1.846 \mu \mathrm{m}$ and $1.049 \mu \mathrm{m}$. The measured maximum and balanced thermal dimension error are $4.39 \mu \mathrm{m}$ and $1.175 \mu \mathrm{m}$, respectively. It is demonstrated that the thermal dimension error of MLUPPS from the proposed model agrees better with measurement results than that from the traditional model, which further validates the proposed model. As aforemen- 


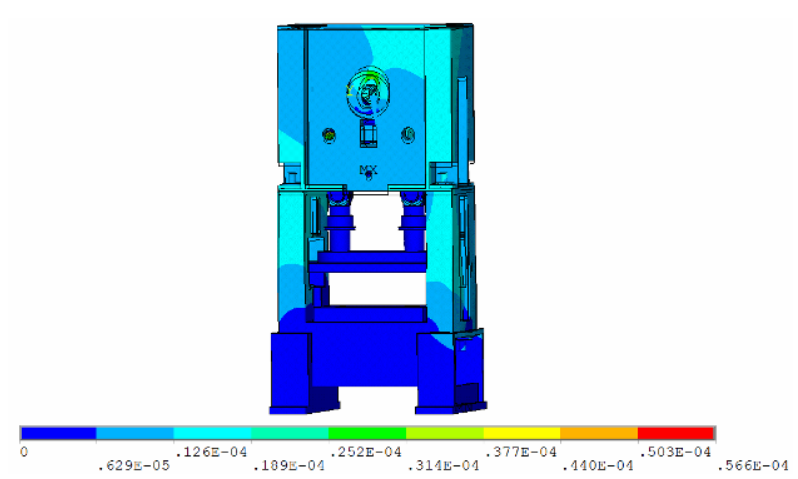

Fig. 21. Thermal displacement of MLUPPS.

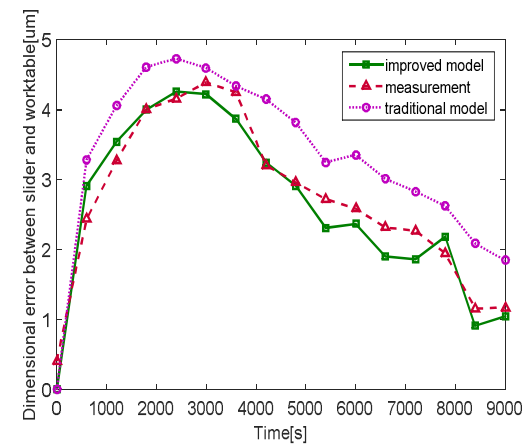

Fig. 22. Thermal dimension error between slider and work table at the position of BDP for MLUPPS.

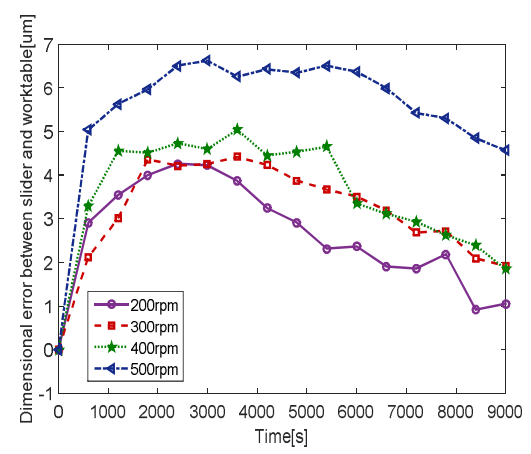

Fig. 23. Thermal dimension error between slider and work table at the position of BDP under different rotation speeds.

tioned, the heat generation from bearing stiffness and flexible crank shaft is considered in the proposed model, and the thermal error for MLUPPS predicted by the proposed model is less than by the traditional model.

\subsubsection{Effect of rotation speed on thermal error}

When the piling force is $300 \mathrm{kN}$ and the stiffness of bearing for crank shaft system is $5 \times 10^{8} \mathrm{~N} / \mathrm{m}$, thermal dimension error between slider and work table for MLUPPS at the position of $\mathrm{BDP}$ with the room temperature of $20^{\circ} \mathrm{C}$ under different rotation speeds of the crank shaft is shown in Fig. 23.

Fig. 23 shows that the thermal dimension error between slider and work table at the position of BDP for MLUPPS generally increases with the increase of rotation speed. The

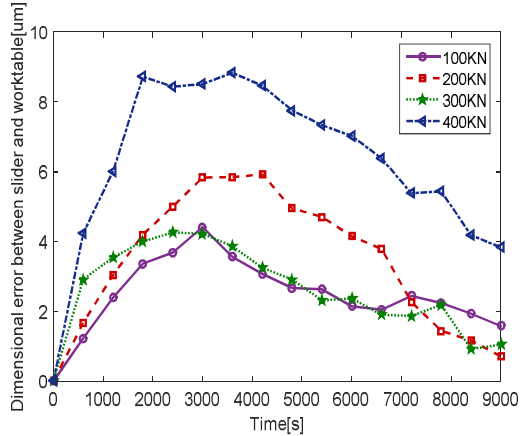

Fig. 24. Thermal dimension error between slider and work table at the position of BDP under different piling forces.

time of maximum thermal dimension error under different rotation speeds of crank shaft occurs at 2400, 3600, 3600 and $3000 \mathrm{~s}$, respectively. When the input speed of crank shaft is increased from $200 \mathrm{rpm}$ to $500 \mathrm{rpm}$, the maximum thermal dimension errors between slider and work table at the position of BDP are $4.258 \mu \mathrm{m}, 4.416 \mu \mathrm{m}, 5.036 \mu \mathrm{m}$ and $6.623 \mu \mathrm{m}$, respectively. When the press system reaches the thermal equilibrium, the thermal dimension errors between slider and work table at the position of BDP are $1.049 \mu \mathrm{m}, 1.914 \mu \mathrm{m}$, $1.846 \mu \mathrm{m}$ and $4.567 \mu \mathrm{m}$. Therefore, $400 \mathrm{rpm}$ is usually a compromise choice between the need for high processing efficiency and machining precision.

\subsubsection{Effect of piling force on thermal error}

When the rotation speed of the crank shaft is $200 \mathrm{rpm}$ and the stiffness of bearing for crank shaft system is $5 \times 10^{8} \mathrm{~N} / \mathrm{m}$, the thermal dimension error between slider and work table for MLUPPS at the position of BDP with the room temperature of $20{ }^{\circ} \mathrm{C}$ under different piling forces is shown in Fig. 24.

It can be seen from Fig. 24 that the thermal dimension error between slider and work table at the position of BDP for MLUPPS initially increases and then decreases with the increase of piling force. The time of maximum thermal dimension error under different piling forces occurs at the 3600 , 4200,3000 and $3600 \mathrm{~s}$. When the piling force increases from $100 \mathrm{kN}$ to $400 \mathrm{kN}$, the maximum thermal dimension error between slider and work table at the position of BDP are $4.41 \mu \mathrm{m}, 5.919 \mu \mathrm{m}, 4.221 \mu \mathrm{m}$ and $8.833 \mu \mathrm{m}$, respectively. When the press system reaches the thermal equilibrium, the thermal dimension errors between slider and work table at the position of BDP are $1.579 \mu \mathrm{m}, 0.7092 \mu \mathrm{m}, 1.049 \mu \mathrm{m}$ and $3.828 \mu \mathrm{m}$. Therefore, when the MLUPPS operates under the working load between 200 and $300 \mathrm{kN}$, the dimensional error as a result of thermal expansion between slider and work table at the position of BDP will reach the minimum.

\subsubsection{Effect of stiffness of bearing on thermal error}

When the input speed of the crank shaft is $200 \mathrm{rpm}$ and the piling force is $300 \mathrm{kN}$, thermal dimension error between slider and work table for MLUPPS at the position of BDP with the room temperature of $20^{\circ} \mathrm{C}$ under different stiffness of bearing 


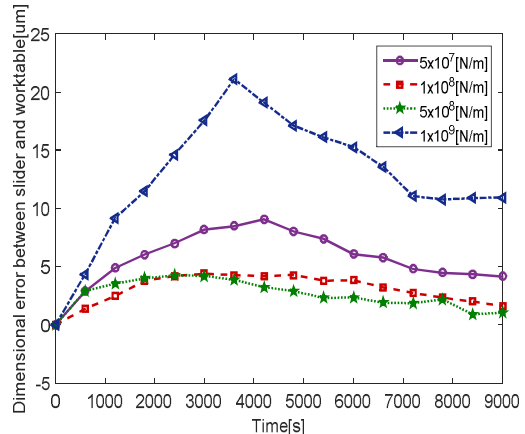

Fig. 25. Thermal dimension error between slider and work table at the position of BDP under different stiffness of bearing.

is shown in Fig. 25.

Fig. 25 shows that the thermal dimension error between slider and work table at the position of BDP for MLUPPS firstly increases and then decreases with the increase of stiffness for bearings of crank shaft system. The time of maximum thermal dimension error occurs at the 4200, 3000, 3000 and $3600 \mathrm{~s}$, respectively. When the stiffness of bearing for crank shaft system increases from $5 \times 10^{7}$ to $1 \times 10^{9} \mathrm{~N} / \mathrm{m}$, the maximum thermal dimension errors between slider and work table at the position of BDP are $9.087 \mu \mathrm{m}, 4.396 \mu \mathrm{m}, 4.221 \mu \mathrm{m}$ and $21.11 \mu \mathrm{m}$, respectively. When the press system reaches the thermal equilibrium, the thermal dimension errors between slider and work table at the position of BDP are $4.156 \mu \mathrm{m}$, $1.625 \mu \mathrm{m}, 1.049 \mu \mathrm{m}$ and $10.96 \mu \mathrm{m}$. Therefore, the optimised stiffness range of bearing for crank shaft system should be between $1 \times 10^{8}$ and $5 \times 10^{8} \mathrm{~N} / \mathrm{m}$ in order to obtain good machining precision.

\section{Conclusions}

In this work, by incorporating the effect of stiffness of bearing and flexibility of crank shaft on the heat generation power, kinematic and dynamic equations of Multi-link transmission mechanism (MLTM) were derived and a flexible dynamic model of crankshaft-bearing system is developed. An improved thermal model of MLUPPS is established by combining the effect of bearings temperature change, thermal contact resistance, stiffness of bearing and flexibility of crank shaft together. The dimension chain of thermal error is then constructed to analyze the dimensional error between the slider and the work table at the position of BDP. The temperature change history and thermal error predicted by the proposed thermal model are in good agreement with the measurement results, and are more accurate than those predicted by the traditional model. The temperature and thermal error are overestimated by traditional model, due to neglection of the heat generation power caused by the bearing stiffness and flexible crank shaft. It is revealed that the thermal dimension error curve between slider and work table at the position of BDP for MLUPPS rises at a relatively rapid speed in the first hour and decreases gradually with a relatively slow speed during the following period. The maximum temperature rise of MLUPPS occurs at the crank shaft, resulting from the accumulated heat generation at the bearing of the crank shaft. Initially, the dimensional error between slider and work table at the position of BDP rises dramatically, and then decreases with the increase of piling force and stiffness of bearing. It is recommended that the optimised stiffness of bearing and piling force should be $\left[1 \times 10^{8}, 5 \times 10^{8} \mathrm{~N} / \mathrm{m}\right]$ and $[200,300 \mathrm{kN}]$, respectively.

Thermal error compensation of the MLUPPS based on the proposed thermal model should be pursued in the future.

\section{Acknowledgment}

This work was supported by the following research projects: "National Natural Science Foundation of China", Grant \# 51405238, "Natural Science Foundation of Jiangsu Province", Grant \# BK20140728, "The Fundamental Research Funds for the Central Universities", Grant \# KYTZ201603, KJQN201558, and "Innovation Fund of Science and Technology for Outstanding Youth from College of Engineering, Nanjing Agricultural University" Grant \# YQ201606, and "Qing Lan Project of Jiangsu Province", Grant \# 80400103.

\section{Nomenclature}

A : Apparent contact area in the contact segment

$h_{c} \quad:$ Coefficient of contact conductance

$L_{g} \quad$ : Thickness of void space between two contact surfaces of joint

$A_{c} \quad$ : Real contact area between two contact surfaces of joint

$A_{\nu} \quad$ : Void area of two contact surfaces in the joint

$k_{1}, k_{2}, k_{f}$ : Thermal contact conductance of two contact parts and the neurogen

$L_{u} \quad$ : Upper boundary of the sample length

$A_{r}^{*} \quad$ : Dimensionless fractional contact area of fractal domain

$A_{r f} \quad$ : Real contact area of the fractal domain

$D \quad$ : Fractal dimension of the surface

$G \quad$ : Fractal roughness parameter

$H \quad$ : Hardness of the softer material between two parts

$P \quad$ : Apparent pressure

$\psi \quad$ : Domain extension factor of microcontact distribution

$E \quad$ : Equivalent elastic modulus

$E_{1}, E_{2} \quad$ : Elastic modulus of the material for the joint

$v_{1}, v_{2} \quad$ : Poisson's ratios of the material for the joint

$z \quad$ : Roughness of the surfaces

$H_{f} \quad$ : Heat generation power

$n \quad$ : Rotation speed of the bearing

$T \quad$ : Sum friction torque acting on bearing

$T_{1} \quad$ : Torque caused by the external force

$T_{2} \quad$ : Torque as a result of the viscosity of lubricant

$T_{3} \quad:$ Spin torque of the bearing

$f_{1} \quad$ : Factor related to the bearing type and load 
$P_{1} \quad$ : Preload of the bearing

$d_{m} \quad$ : Average diameter of the bearing

$F_{a} \quad:$ : Axial force acting on the bearing

$F_{r} \quad$ : Radial force acting on the bearing

$f_{0} \quad$ : Type of bearings and lubrication type

$v_{0} \quad$ : Motion viscosity of lube

$\mu \quad$ : Friction coefficient between ball and raceway

$Q \quad$ : Load on single rolling element

$\xi \quad:$ : Elliptic integral of the second kind

a : Semi-major axis of hertz contact ellipse in raceway

$k_{\text {fluid }} \quad$ : Heat conduction of ambient air

$N_{u} \quad$ : Nusselt number

$R_{e} \quad:$ Reynolds number

$P_{r} \quad$ : Prandtl number

$G_{r} \quad:$ Gratchev number

$u_{\text {fluid }} \quad$ : Flow velocity of ambient air

$c_{\text {fluid }} \quad$ : Specific heat capacitance of ambient air

$\mu_{\text {fluid }} \quad$ : Dynamic viscosity of ambient air

$v_{\text {fluid }} \quad$ : Motion viscosity of ambient air

$\Delta t \quad:$ Temperature rise

d $\quad$ : Diameter of disk

$g \quad$ : Acceleration of gravity

$L \quad$ : Length of rotating body

$M_{y}, M_{z}:$ Distributed moments along axis y and $\mathrm{z}$

$q_{x}, q_{y}, q_{z}$ : Distributed loads along the directions $\mathrm{x}, \mathrm{y}$ and $\mathrm{z}$

$\theta_{y}, \theta_{z} \quad$ : Rotational angle along the axes $\mathrm{y}$ and $\mathrm{z}$

$\rho \quad$ : Density of crank shaft

$u, v, w$ : Displacement along the directions $\mathrm{x}, \mathrm{y}$ and $\mathrm{z}$

$m_{D} \quad$ : Mass of disk

$e \quad$ : Distance between mass centre and the geometrical centre of the disk

$\omega \quad$ : Angular velocity of crank shaft

$t \quad$ : Thickness of disk

$k_{s} \quad:$ Transverse shear form factor, $k_{\mathrm{s}}=0.9$

D : Diameter of crank shaft

$I_{s} \quad$ : Inertia moment of crank shaft

$E_{s} \quad:$ : Elastic modulus of crank shaft

$A_{\mathrm{s}} \quad$ : Area of cross-section of crank shaft

$[M]_{T},[M]_{R}$ : Translational and rotational mass matrix

$\left[M^{b}\right]_{C} \quad$ : Mass matrix to compute the centrifugal force

$\left[G^{b}\right] \quad:$ Gyroscopic matrix

$\left[K^{b}\right]_{P} \quad$ : Stiffness matrix as a result of axial load

$F \quad$ : Force acting on the big pulley due to belt

$P_{m} \quad$ : Power of motor

$d_{1} \quad$ : Diameter of big pulley

$v \quad$ : Velocity of belt

$m \quad$ : Mass of big pulley

\section{References}

[1] L. Wang, Z. M. Ke, F. Jia and X. S. Wang, Temperature field simulation and experiment research of high speed press, Duanya Jishu, 36 (4) (2011) 80-84.

[2] B. Bossmanns and J. F. Tu, A thermal model for high speed motorized spindles, International Journal of Machine Tools and Manufacture, 39 (9) (1999) 1345-1366.

[3] B. Bossmanns and J. F. Tu, A power flow model for high speed motorized spindles-heat generation characterization, Journal of Manufacturing Science and Engineering, ASME, 123 (3) (2001) 494-505.

[4] J. S. Chen and W. Y. Hsu, Characterizations and models for the thermal growth of a motorized high speed spindle, International Journal of Machine Tools and Manufacture, 43 (11) (2003) 1163-1170.

[5] C. W. Lin, J. F. Tu and J. Kamman, An integrated thermomechanical-dynamic model to characterize motorized machine tool spindles during very high speed rotation, International Journal of Machine Tools and Manufacture, 43 (10) (2003) 1035-1050.

[6] B. R. Jorgensen and Y. C. Shin, Dynamics of machine tool spindle/bearing systems under thermal growth, Journal of Tribology, ASME, 119 (4) (1997) 875-882.

[7] H. Q. Li and Y. C. Shin, Analysis of bearing configuration effects on high speed spindles using an integrated dynamic thermo-mechanical spindle model, International Journal of Machine Tools and Manufacture, 44 (4) (2004) 347-364.

[8] H. T. Zhao, J. G. Yang and J. H. Shen, Simulation of thermal behavior of a $\mathrm{CNC}$ machine tool spindle, International Journal of Machine Tools and Manufacture, 47 (6) (2007) 1003-1010.

[9] M. Xu, S. Y. Jiang and Y. Cai, An improved thermal model for machine tool bearings, International Journal of Machine Tools and Manufacture, 47 (1) (2007) 53-62.

[10] E. Creighton, A. Honegger, A. Tulsian and D. Mukhopadhyay, Analysis of thermal errors in a high-speed micro-milling spindle, International Journal of Machine Tools and Manufacture, 50 (4) (2010) 386-393.

[11] T. Holkup, H. Cao, P. Koláŕ, Y. Altintas and J. Zelený, Thermo-mechanical model of spindles, CIRP AnnalsManufacturing Technology, 59 (1) (2010) 365-368.

[12] A. Zahedi and M. R. Movahhedy, Thermo-mechanical modeling of high speed spindles, Scientia Iranica, 19 (2) (2012) 282-293.

[13] C. L. Zhao and X. S. Guan, Thermal analysis and experimental study on the spindle of the high-speed machining center, AASRI Procedia, 1 (2012) 207-212.

[14] J. Lee, D. H. Kim and C. M. Lee, A study on the thermal characteristics and experiments of high-speed spindle for machine tools, International Journal of Precision Engineering and Manufacturing, 16 (2) (2015) 293-299.

[15] C. Ma, J. Yang, L. Zhao, X. Mei and H. Shi, Simulation and experimental study on the thermally induced deformations of high-speed spindle system, Applied Thermal Engineering, 86 (2015) 251-268.

[16] Z. C. Du, S. Y. Yao and J. G. Yang, Thermal behavior analysis and thermal error compensation for motorized spindle of machine tools, International Journal of Precision Engineering and Manufacturing, 16 (7) (2015) 1571-1581.

[17] D. X. Li, P. F. Feng and J. F. Zhang, Simulation, experiment and optimization for thermal characteristics of a ma- 
chine tool spindle system, Key Engineering Materials, 693 (2016) 403-410.

[18] J. J. Kim, Y. H. Jevon and D. W. Cho, Thermal behavior of a machine tool equipped with linear motors, International Journal of Machine Tools and Manufacture, 44 (7) (2004) 749-758.

[19] B. Shen, A. J. Shih and G. Xiao, A heat transfer model based on finite difference method for grinding, Journal of Manufacturing Science and Engineering, 133 (3) (2011) 110.

[20] L. Wang, F. Y. Xu and X. S. Wang, Analysis of thermally induced machine tool errors of a crank press, Proceedings of the Institution of Mechanical Engineers, Part B: Journal of Engineering Manufacture, 226 (9) (2012) 1465-1478.

[21] L. Wang, Z. M. Ke, F. Jia and X. S. Wang, Temperature field simulation and experiment research of high speed press, Forging \& Stamping Technology, 36 (4) (2011) 80-84.

[22] T. Maier and M. F. Zaeh, Modeling of the thermomechanical process effects on machine tool structures, Procedia CIRP, 4 (2012) 73-78.

[23] M. Tang and F. Jia. Temperature field simulation on the connecting rod of high speed press, 3rd International Conference on Manufacturing Science and Engineering, Xiamen, China (2012) 322-326.

[24] Y. Chen, Y. Sun and W. X. Ding, Thermo-mechanical coupling model and dynamical characteristics of press actuator, Procedia Engineering, 81 (2014) 1657-1662.

[25] F. F. Hu, Y. Sun and B. B. Peng, Dynamic characteristics analysis and experimental verification of high-speed precision punch press based on coupled thermal-mechanical model, Procedia Engineering, 81 (2014) 1651-1656.

[26] Z. Chval, Effect of heat load on a forging press, Procedia Engineering, 69 (2014) 897-901.

[27] E. L. Zheng, F. Jia and S. H. Zhu, Thermal modelling and characteristics analysis of high speed press system, International Journal of Machine Tools and Manufacture, 85 (2014) 87-99.

[28] L. Y. Kong, Simulation, experiment, and optimization method for thermal characteristics of machine tool, Heat Transfer-Asian Research (2016) Doi: 10.1002/htj.21229.

[29] E. L. Zheng, F. Jia, Z. S. Zhang and J. F. Shi, Load spectrum analysis for combined frame of closed high-speed press, Journal of Southeast University, 27 (2011) 40-46.

[30] J. P. Holman, Heat transfer, Eighth Ed., McGraw-Hill, New York, USA (2001).

[31] S. Wang, Real contact area of fractal-regular surfaces and its implications in the law of friction, Journal of Tribology, ASME, 126 (2004) 1-8.

[32] T. A. Harris, Rolling Bearing Analysis, Wiley Sons, New York, USA (1991).

[33] D. J. Cheng, J. H. Park, J. S. Suh, S. J. Kim and C. H. Park, Effect of frictional heat generation on the temperature distribution in roller linear motion rail surface, Journal of Mechanical Science and Technology, 31 (3) (2017) 1477-1487.

[34] H. Li and Y. C. Shin, Integrated dynamic thermo- mechanical modeling of high speed spindles, Part 1: Model development, Journal of Manufacturing Science and Engineering, ASME, 126 (1) (2004) 148-158.

[35] J. K. Choi and D. G. Lee, Thermal characteristics of the spindle bearing system with a gear located on the bearing span, International Journal of Machine Tools and Manufacture, 38 (9) (1998) 1017-1030.

\section{Appendix}

\section{A.1 Kinematic analysis of MLTM}

The kinematic analysis diagram of MLTM is shown in Fig. A.1 and its parameters are shown in Table A.1. As shown in Fig. A.1(a), the position, velocity and acceleration for the hinge joint $\mathrm{P}_{23}$ between the crank shaft 2 and the linkage 3 can be given by:

$$
\left\{\begin{array}{l}
x_{23}=l_{2} \cos \varphi \\
y_{23}=l_{2} \sin \varphi
\end{array},\left\{\begin{array}{l}
\dot{x}_{23}=-l_{2} \omega \sin \varphi \\
\dot{y}_{23}=l_{2} \omega \cos \varphi
\end{array},\left\{\begin{array}{l}
\ddot{x}_{23}=-l_{2} \omega^{2} \cos \varphi \\
\ddot{y}_{23}=-l_{2} \omega^{2} \sin \varphi
\end{array} .\right.\right.\right.
$$

Similarly, the position, velocity and acceleration of the mass center $\mathrm{P}_{2 \mathrm{c}}$ for the crank shaft 2 can be expressed by:

$$
\left\{\begin{array}{l}
x_{2 c}=\xi_{2} \cos \varphi \\
y_{2 c}=\xi_{2} \sin \varphi
\end{array},\left\{\begin{array}{l}
\dot{x}_{2 c}=-\xi_{2} \omega \sin \varphi \\
\dot{y}_{2 c}=\xi_{2} \omega \cos \varphi
\end{array},\left\{\begin{array}{l}
\ddot{x}_{2 c}=-\xi_{2} \omega^{2} \cos \varphi \\
\ddot{y}_{2 c}=-\xi_{2} \omega^{2} \sin \varphi .
\end{array}\right.\right.\right.
$$

Since the position of the slider 4 in the horizontal direction keeps constant, its velocity and acceleration along horizontal direction is also zero. Then, the position, velocity and acceleration for the hinge joint $\mathrm{P}_{34}$ between the linkage 3 and the slider 4 shown in Fig. A.1(b) are expressed as:

$$
\begin{aligned}
& \left\{\begin{array}{l}
x_{34}=x_{23}+l_{3} \cos \varphi_{3} \\
y_{34}=y_{23}+l_{3} \sin \varphi_{3}
\end{array},\left\{\begin{array}{l}
\dot{x}_{34}=0 \\
\dot{y}_{34}=\dot{y}_{23}+l_{3} \dot{\varphi}_{3} \cos \varphi_{3}
\end{array},\right.\right. \\
& \left\{\begin{array}{l}
\ddot{x}_{34}=0 \\
\ddot{y}_{34}=\ddot{y}_{23}-l_{3} \dot{\varphi}_{3}^{2} \sin \varphi_{3}+l_{3} \ddot{\varphi}_{3} \cos \varphi_{3}
\end{array}\right.
\end{aligned}
$$

where $\varphi_{3}=\arccos \frac{-x_{23}}{l_{3}}, \dot{\varphi}_{3}=\frac{\dot{x}_{23}}{l_{3} \sin \varphi_{3}}$, $\ddot{\varphi}_{3}=\frac{\ddot{x}_{23}}{l_{3} \sin \varphi_{3}}-\frac{\dot{x}_{23} \dot{\varphi}_{3} \cos \varphi_{3}}{l_{3} \sin ^{2} \varphi_{3}}$.

Based on the geometrical relationship shown in Fig. A.1(c), the vertical distance between hinge joint $\mathrm{P}_{34}$ and $\mathrm{H}$ is expressed as:

$$
\varsigma=y_{34}-y_{H} .
$$

The angle of rotation for swing link 5 is derived based on cosine law. Then,

$$
\varphi_{5}=\frac{3}{2} \pi-\arccos \frac{l_{5 a}^{2}+\varsigma^{2}-l_{6}^{2}}{2 l_{5 a} \varsigma} .
$$


Table A.1. Parameters of MLTM.

\begin{tabular}{|c|c|c|c|c|c|}
\hline Parameter & Value & Parameter & Value & Parameter & Value \\
\hline$l_{2}$ & $25 \mathrm{~mm}$ & $\xi_{7}$ & $70.7314 \mathrm{~mm}$ & $m_{4}$ & $22.202 \mathrm{~kg}$ \\
\hline$l_{3}$ & $383 \mathrm{~mm}$ & $\xi_{8}$ & $11.5918 \mathrm{~mm}$ & $m_{5}$ & $25.824 \mathrm{~kg}$ \\
\hline$l_{5}$ & $350 \mathrm{~mm}$ & $\xi_{9}$ & $85.9316 \mathrm{~mm}$ & $m_{6}$ & $33.265 \mathrm{~kg}$ \\
\hline$l_{6}$ & $240 \mathrm{~mm}$ & $\xi_{11}$ & $116.910 \mathrm{~mm}$ & $m_{7}$ & $15.516 \mathrm{~kg}$ \\
\hline$l_{7}$ & $163.8 \mathrm{~mm}$ & $\mathrm{y}_{18}$ & $440 \mathrm{~mm}$ & $m_{8}$ & $155.350 \mathrm{~kg}$ \\
\hline$l_{8}$ & $550 \mathrm{~mm}$ & $\mathrm{y}_{\mathrm{H}}$ & $798.17 \mathrm{~mm}$ & $m_{9}$ & $39.871 \mathrm{~kg}$ \\
\hline$l_{9}$ & $275 \mathrm{~mm}$ & $\mathrm{X}_{910}$ & $370 \mathrm{~mm}$ & $m_{10}$ & $1322.481 \mathrm{~kg}$ \\
\hline$l_{11}$ & $275 \mathrm{~mm}$ & $\mathrm{X}_{112}$ & $410 \mathrm{~mm}$ & $m_{11}$ & $22.590 \mathrm{~kg}$ \\
\hline$\xi_{2}$ & $13.7512 \mathrm{~mm}$ & $\mathrm{x}_{18}$ & $390 \mathrm{~mm}$ & $m_{12}$ & $193.633 \mathrm{~kg}$ \\
\hline$\xi_{3}$ & $156.991 \mathrm{~mm}$ & $m_{2}$ & $217.617 \mathrm{~kg}$ & $\xi_{6}$ & $140.219 \mathrm{~mm}$ \\
\hline$\xi_{5}$ & $175.301 \mathrm{~mm}$ & $m_{3}$ & $184.531 \mathrm{~kg}$ & - & - \\
\hline
\end{tabular}

Differentiating Eq. (A.5) yields the angular velocity and acceleration.

$$
\begin{aligned}
\dot{\varphi}_{5}= & \frac{-l_{5 a} \cos \beta+\varsigma}{l_{5 a} \varsigma \sin \beta} \dot{y}_{34} \\
\ddot{\varphi}_{5}= & {\left[\left(-l_{5 a} \cos \beta+\varsigma\right) \ddot{y}_{34}\right] /\left(l_{5 a} \varsigma \sin \beta\right)+\left[\left(\xi^{2} \dot{\varphi}_{5} \cos \beta\right.\right.} \\
& \left.\left.-l_{5 a} \varsigma \dot{\varphi}_{5}+l_{5 a} \dot{y}_{34} \sin \beta \cos \beta\right) \dot{y}_{34}\right] /\left(l_{5 a} \varsigma^{2} \sin ^{2} \beta\right) .
\end{aligned}
$$

The position, velocity and acceleration for the hinge joint $\mathrm{P}_{57}$ between the swing link 5 and the linkage 7 in can be expressed as:

$$
\begin{aligned}
& \left\{\begin{array}{l}
x_{57}=l_{5} \cos \varphi_{5} \\
y_{57}=y_{34}+l_{5} \sin \varphi_{5}
\end{array}\right. \\
& \left\{\begin{array}{l}
\dot{x}_{57}=-l_{5} \dot{\varphi}_{5} \sin \varphi_{5} \\
\dot{y}_{57}=\dot{y}_{34}+l_{5} \dot{\varphi}_{5} \cos \varphi_{5}
\end{array}\right. \\
& \left\{\begin{array}{l}
\ddot{x}_{57}=-l_{5} \dot{\varphi}_{5}^{2} \cos \varphi_{5}-l_{5} \ddot{\varphi}_{5} \sin \varphi_{5} \\
\ddot{y}_{57}=\ddot{y}_{34}-l_{5} \dot{\varphi}_{5}^{2} \sin \varphi_{5}+l_{5} \ddot{\varphi}_{5} \cos \varphi_{5} .
\end{array}\right.
\end{aligned}
$$

Similarly, the position, velocity and acceleration of the mass center $\mathrm{P}_{5 \mathrm{c}}$ for the swing link 5 can also be expressed by:

$$
\begin{aligned}
& \left\{\begin{array}{l}
x_{5 c}=\xi_{5} \cos \varphi_{5} \\
y_{5 c}=y_{34}+\xi_{5} \sin \varphi_{5}
\end{array}\right. \\
& \left\{\begin{array}{l}
\dot{x}_{5 c}=-\xi_{5} \dot{\varphi}_{5} \sin \varphi_{5} \\
\dot{y}_{5 c}=\dot{y}_{34}+\xi_{5} \dot{\varphi}_{5} \cos \varphi_{5}
\end{array}\right. \\
& \left\{\begin{array}{l}
\ddot{x}_{5 c}=-\xi_{5} \dot{\varphi}_{5}^{2} \cos \varphi_{5}-\xi_{5} \ddot{\varphi}_{5} \sin \varphi_{5} \\
\ddot{y}_{5 c}=\ddot{y}_{34}-\xi_{5} \dot{\varphi}_{5}^{2} \sin \varphi_{5}+\xi_{5} \ddot{\varphi}_{5} \cos \varphi_{5} .
\end{array}\right.
\end{aligned}
$$

The angle of rotation, angular velocity and acceleration for support link 6 shown in Fig. A.1(d) also can be derived based on cosine law. Then,

$$
\begin{aligned}
& \varphi_{6}=\arccos \frac{l_{6}^{2}+\varsigma^{2}-l_{5 a}^{2}}{2 l_{6} \zeta}, \dot{\varphi}_{6}=\frac{l_{6} \cos \varphi_{6}-\zeta}{l_{6} \zeta \sin \varphi_{6}} \dot{y}_{34}, \\
& \ddot{\varphi}_{6}=\frac{l_{6} \cos \varphi_{6}-\zeta}{l_{6} \zeta \sin \varphi_{6}} \ddot{y}_{34}+\frac{\zeta^{2} \dot{\varphi}_{6} \cos \varphi_{6}-l_{6} \zeta \dot{\varphi}_{6}-l_{6} \dot{y}_{34} \sin \varphi_{6} \cos \varphi_{6}}{l_{6} \zeta^{2} \sin ^{2} \varphi_{6}} \dot{y}_{34} .
\end{aligned}
$$

The position, velocity and acceleration of the mass center $\mathrm{P}_{6 c}$ for support link 6 can be given by:

$$
\begin{aligned}
& \left\{\begin{array}{l}
x_{6 c}=-\xi_{6} \sin \varphi_{6} \\
y_{6 c}=\xi_{6} \cos \varphi_{6}+y_{H}
\end{array}\right. \\
& \left\{\begin{array}{l}
\dot{x}_{6 c}=-\xi_{6} \dot{\varphi}_{6} \cos \varphi_{6} \\
\dot{y}_{6 c}=-\xi_{6} \dot{\varphi}_{6} \sin \varphi_{6}
\end{array}\right. \\
& \left\{\begin{array}{l}
\ddot{x}_{6 c}=\xi_{6} \dot{\varphi}_{6}^{2} \sin \varphi_{6}-\xi_{6} \ddot{\varphi}_{6} \cos \varphi_{6} \\
\ddot{y}_{6 c}=-\xi_{6} \dot{\varphi}_{6}^{2} \cos \varphi_{6}-\xi_{6} \ddot{\varphi}_{6} \sin \varphi_{6} .
\end{array}\right.
\end{aligned}
$$

The position for the hinge joint $\mathrm{P}_{78}$ between linkage 7 and 8 shown in Fig. A.1(e) can be given by:

$$
\left\{\begin{array}{l}
x_{78}=x_{57}+l_{7} \cos \varphi_{7}=x_{18}+l_{8 b} \cos \varphi_{8} \\
y_{78}=y_{57}+l_{7} \sin \varphi_{7}=x_{18}+l_{8 b} \sin \varphi_{8} .
\end{array}\right.
$$

It is assumed that $D=\left(B^{2}+C^{2}+l_{8}^{2}-l_{7}^{2}\right) / 2 l_{8 b}, B=x_{18}-x_{57}$, $C=y_{18}-y_{57}$. Then, Eq. (A.11) can be rewritten as:

$$
B \cos \varphi_{8}+C \sin \varphi_{8}+D=0 .
$$

Solving Eq. (A.12) yields the rotation angle $\varphi_{8}$ of linkage 8,

$$
\varphi_{81,82}=2 \pi+2 \arccos \frac{-C \pm \sqrt{C^{2}+B^{2}-D^{2}}}{D-B} .
$$

Due to high stamp speed of MLUPPS, swing amplitude of linkage 8 is very small. Therefore, the rotation angle $\varphi_{8}$ of linkage 8 is calculated by: 


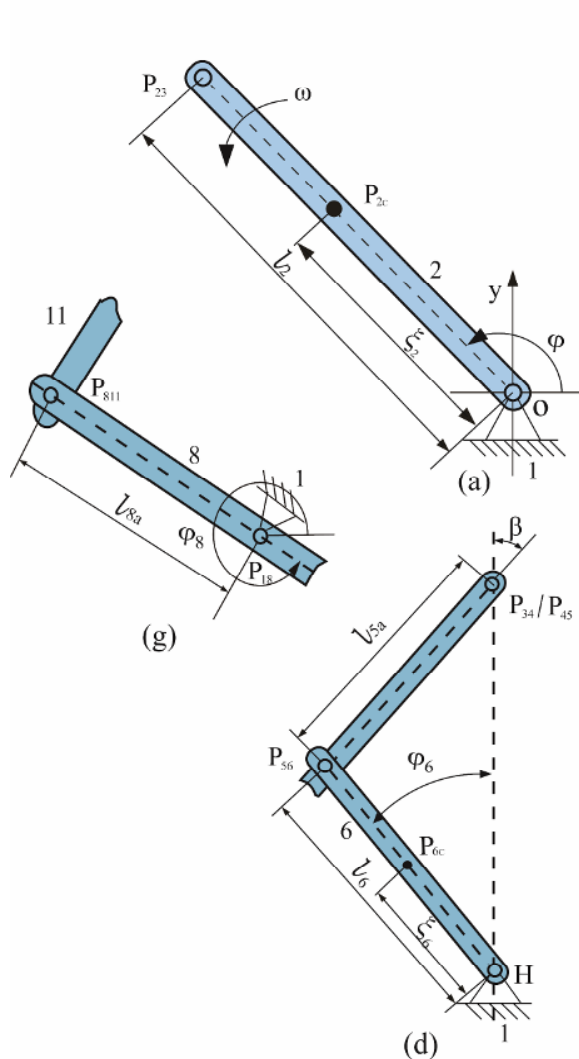

(d)

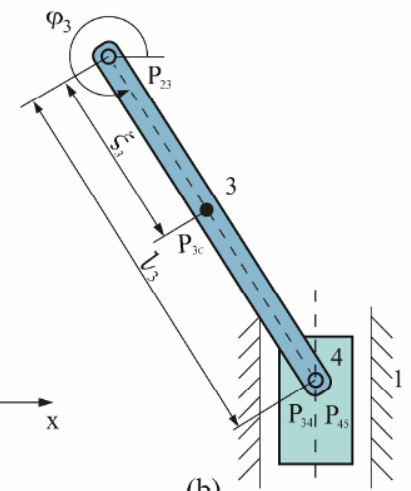

(b)

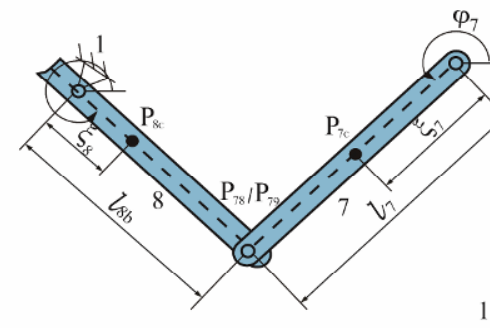

(e)

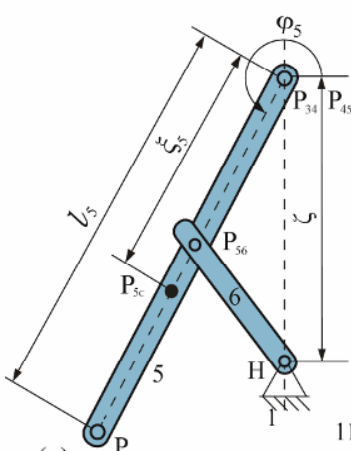

(c)

Fig. A.1. Kinematic analysis diagram of MLTM.

$$
\varphi_{8}= \begin{cases}\varphi_{81} & \left|3 \pi / 2-\varphi_{81}\right| \leq\left|3 \pi / 2-\varphi_{82}\right| \\ \varphi_{82} & \left|3 \pi / 2-\varphi_{81}\right|>\left|3 \pi / 2-\varphi_{82}\right|\end{cases}
$$

Differentiating Eq. (A.14) yields:

$$
\begin{aligned}
\dot{\varphi}_{8}= & \frac{\dot{B} \cos \varphi_{8}+\dot{C} \sin \varphi_{8}+\dot{D}}{B \sin \varphi_{8}-C \cos \varphi_{8}} \\
\ddot{\varphi}_{8}= & \frac{\ddot{B} \cos \varphi_{8}+\ddot{C} \sin \varphi_{8}+\ddot{D}-B \dot{\varphi}_{8} \sin \varphi_{8}+C \dot{\varphi}_{8} \cos \varphi_{8}}{B \sin \varphi_{8}-C \cos \varphi_{8}} \\
& -\frac{\left(\dot{B} \sin \varphi_{8}+B \dot{\varphi}_{8} \cos \varphi_{8}-\dot{C} \cos \varphi_{8}+C \dot{\varphi}_{8} \sin \varphi_{8}\right) \times\left(\dot{B} \cos \varphi_{8}+\dot{C} \sin \varphi_{8}+\dot{D}\right)}{\left(B \sin \varphi_{8}-C \cos \varphi_{8}\right)^{2}}
\end{aligned}
$$

where $\dot{B}=-\dot{x}_{57}, \dot{C}=-\dot{y}_{57}, \dot{D}=(B \dot{B}+C \dot{C}) / l_{8 b}$, $\ddot{B}=-\ddot{x}_{57}, \ddot{C}=-\ddot{y}_{57}, \quad \ddot{D}=\left(B^{2}+B \ddot{B}+C^{2}+C \ddot{C}\right) / l_{8 b}$.

The velocity and acceleration for hinge joint $\mathrm{P}_{78}$ between the linkage 7 and 8 can also be given by:

$$
\left\{\begin{array}{l}
\dot{x}_{78}=-l_{8 b} \dot{\varphi}_{8} \sin \varphi_{8} \\
\dot{y}_{78}=l_{8 b} \dot{\varphi}_{8} \cos \varphi_{8}
\end{array},\left\{\begin{array}{l}
\ddot{x}_{78}=-l_{8 b} \dot{\varphi}_{8}^{2} \cos \varphi_{8}-l_{8 b} \ddot{\varphi}_{8} \sin \varphi_{8} \\
\ddot{y}_{78}=-l_{8 b} \dot{\varphi}_{8}^{2} \sin \varphi_{8}+l_{8 b} \ddot{\varphi}_{8} \cos \varphi_{8} .
\end{array}\right.\right.
$$

The position, velocity and acceleration of the mass center $\mathrm{P}_{8 \mathrm{c}}$ for the linkage 8 can be given by:

$$
\begin{aligned}
& \left\{\begin{array}{l}
x_{8 c}=x_{18}+\xi_{8} \cos \varphi_{8} \\
y_{8 c}=y_{18}+\xi_{8} \sin \varphi_{8}
\end{array}\right. \\
& \left\{\begin{array}{l}
\dot{x}_{8 c}=-\xi_{8} \dot{\varphi}_{8} \sin \varphi_{8} \\
\dot{y}_{8 c}=\xi_{8} \dot{\varphi}_{8} \cos \varphi_{8}
\end{array}\right. \\
& \left\{\begin{array}{l}
\ddot{x}_{8 c}=-\xi_{8} \dot{\varphi}_{8}^{2} \cos \varphi_{8}-\xi_{8} \ddot{\varphi}_{8} \sin \varphi_{8} \\
\ddot{y}_{8 c}=-\xi_{8} \dot{\varphi}_{8}^{2} \sin \varphi_{8}+\xi_{8} \ddot{\varphi}_{8} \cos \varphi_{8} .
\end{array}\right.
\end{aligned}
$$

The angle of rotation, angular velocity and acceleration for the linkage 7 can be expressed as:

$$
\begin{aligned}
\varphi_{7}= & \arctan \frac{C+l_{8 b} \sin \varphi_{8}}{B+l_{8 b} \cos \varphi_{8}} \\
\dot{\varphi}_{7}= & \frac{l_{8 b} \dot{\varphi}_{8} \cos \varphi_{8}-\dot{y}_{57}}{l_{7} \cos \varphi_{7}} \\
\ddot{\varphi}_{7}= & \left(l_{8 b} \ddot{\varphi}_{8} \cos \varphi_{8}-l_{8 b} \dot{\varphi}_{8}^{2} \sin \varphi_{8}-\ddot{y}_{57}\right) /\left(l_{7} \cos \varphi_{7}\right) \\
& +\left[\sin \varphi_{7}\left(l_{8 b} \dot{\varphi}_{8} \cos \varphi_{8}-\dot{y}_{57}\right) \dot{\varphi}_{7}\right] /\left(l_{7} \cos ^{2} \varphi_{7}\right) .
\end{aligned}
$$

The position, velocity and acceleration of the mass center $\mathrm{P}_{7 \mathrm{c}}$ for the linkage 7 can be given by:

$$
\left\{\begin{array}{l}
x_{7 c}=x_{57}+\xi_{7} \cos \varphi_{7} \\
y_{7 c}=y_{57}+\xi_{7} \sin \varphi_{7}
\end{array}\right.
$$




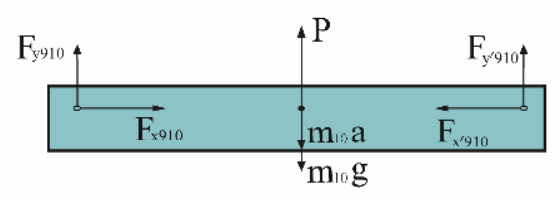

(a)
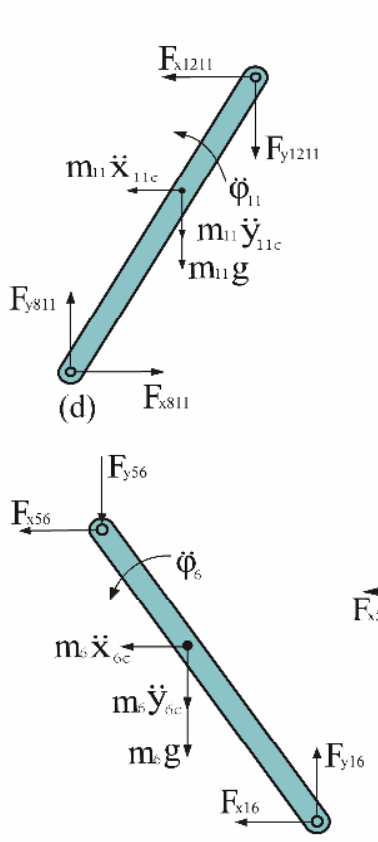

(h)

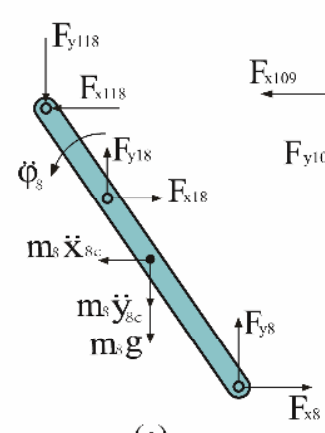

(e)

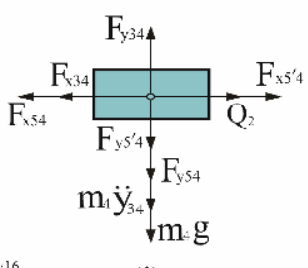

(i)

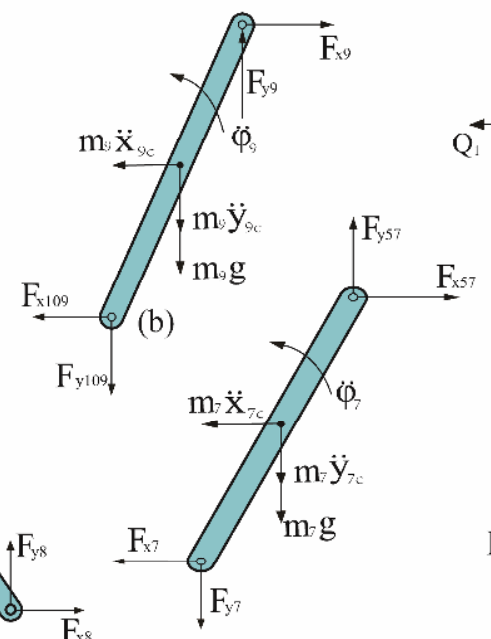

(f)

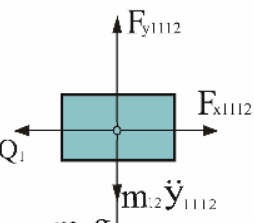

$\mathrm{m}_{12} \mathrm{~g}$

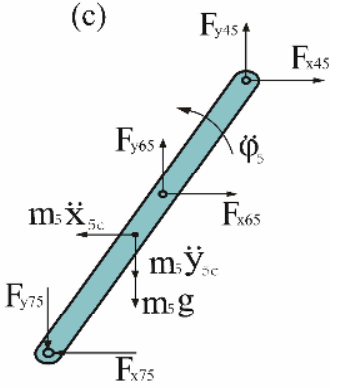

(g)
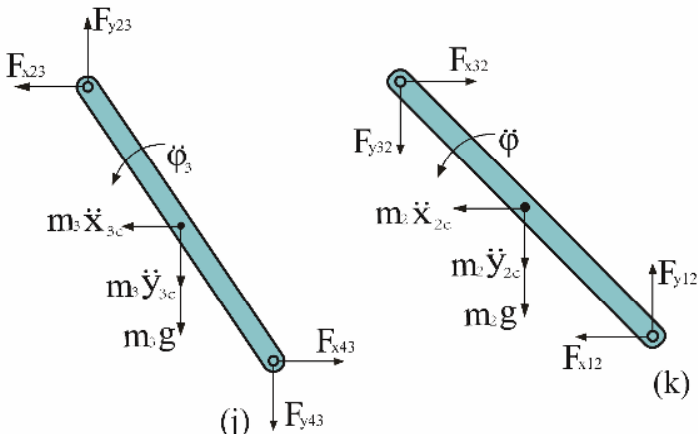

(k)

Fig. A.2. Dynamic analysis diagram of MLTM.

$$
\begin{gathered}
\left\{\begin{array}{l}
\dot{x}_{7 c}=\dot{x}_{57}-\xi_{7} \dot{\varphi}_{7} \sin \varphi_{7} \\
\dot{y}_{7 c}=\dot{y}_{57}+\xi_{7} \dot{\varphi}_{7} \cos \varphi_{7}
\end{array}\right. \\
\left\{\begin{array}{l}
\ddot{x}_{7 c}=\ddot{x}_{57}-\xi_{7} \dot{\varphi}_{7}^{2} \cos \varphi_{7}-\xi_{7} \ddot{\varphi}_{7} \sin \varphi_{7} \\
\ddot{y}_{7 c}=\ddot{y}_{57}-\xi_{7} \dot{\varphi}_{7}^{2} \sin \varphi_{7}+\xi_{7} \ddot{\varphi}_{7} \cos \varphi_{7} .
\end{array}\right.
\end{gathered}
$$

The position, velocity and acceleration for the hinge joint $\mathrm{P}_{910}$ between the linkage 9 and slider 10 shown in Fig. A.1(f) are given by:

$$
\begin{aligned}
& \left\{\begin{array}{l}
x_{910}=x_{78}+l_{9} \cos \varphi_{9} \\
y_{910}=y_{78}+l_{9} \sin \varphi_{9}
\end{array}, \quad\left\{\begin{array}{l}
\dot{x}_{910}=0 \\
\dot{y}_{910}=\dot{y}_{78}+l_{9} \dot{\varphi}_{9} \cos \varphi_{9}
\end{array}\right.\right. \\
& \left\{\begin{array}{l}
\ddot{x}_{910}=0 \\
\ddot{y}_{910}=\ddot{y}_{78}-l_{9} \dot{\varphi}_{9}^{2} \sin \varphi_{9}+l_{9} \ddot{\varphi}_{9} \cos \varphi_{9}
\end{array}\right.
\end{aligned}
$$

where $E=\frac{x_{910}-x_{78}}{l_{9}}, \varphi_{9}=2 \pi-2 \arctan \sqrt{\frac{1-E}{1+E}}, \dot{\varphi}_{9}=\frac{\dot{x}_{78}}{l_{9} \sin \varphi_{9}}$, $\ddot{\varphi}_{9}=\frac{\ddot{x}_{78} \sin \varphi_{9}-\dot{x}_{78} \dot{\varphi}_{9} \cos \varphi_{9}}{l_{9} \sin ^{2} \varphi_{9}}$

The position, velocity and acceleration of the mass center $P_{9 c}$ for the linkage 9 can be given by:

$$
\begin{aligned}
& \left\{\begin{array}{l}
x_{9 c}=x_{78}+\xi_{9} \cos \varphi_{9} \\
y_{9 c}=y_{78}+\xi_{9} \sin \varphi_{9}
\end{array}\right. \\
& \left\{\begin{array}{l}
\dot{x}_{9 c}=\dot{x}_{78}-\xi_{9} \dot{\varphi}_{9} \sin \varphi_{9} \\
\dot{y}_{9 c}=\dot{y}_{78}+\xi_{9} \dot{\varphi}_{9} \cos \varphi_{9}
\end{array}\right. \\
& \left\{\begin{array}{l}
\ddot{x}_{9 c}=\ddot{x}_{78}-\xi_{9} \dot{\varphi}_{9}^{2} \cos \varphi_{9}-\xi_{9} \ddot{\varphi}_{9} \sin \varphi_{9} \\
\ddot{y}_{9 c}=\ddot{y}_{78}-\xi_{9} \dot{\varphi}_{9}^{2} \sin \varphi_{9}+\xi_{9} \ddot{\varphi}_{9} \cos \varphi_{9} .
\end{array}\right.
\end{aligned}
$$

The position, velocity and acceleration for the hinge joint $\mathrm{P}_{811}$ between the linkage 8 and 11 shown in Fig. A.1(g) are given by:

$$
\begin{gathered}
\left\{\begin{array}{l}
x_{811}=x_{18}-l_{8 a} \cos \varphi_{8} \\
y_{811}=y_{18}-l_{8 a} \sin \varphi_{8}
\end{array}\right. \\
\left\{\begin{array}{l}
\dot{x}_{811}=l_{8 a} \dot{\varphi}_{8} \sin \varphi_{8} \\
\dot{y}_{811}=-l_{8 a} \dot{\varphi}_{8} \cos \varphi_{8}
\end{array}\right. \\
\left\{\begin{array}{l}
\ddot{x}_{811}=l_{8 a} \dot{\varphi}_{8}^{2} \cos \varphi_{8}+l_{8 a} \ddot{\varphi}_{8} \sin \varphi_{8} \\
\ddot{y}_{811}=l_{8 a} \dot{\varphi}_{8}^{2} \sin \varphi_{8}-l_{8 a} \ddot{\varphi}_{8} \cos \varphi_{8} .
\end{array}\right.
\end{gathered}
$$

The position, velocity and acceleration for the hinge joint $\mathrm{P}_{1112}$ between the linkage 11 and slider 12 shown in Fig. A.1(h) are given by: 


$$
\begin{aligned}
& \left\{\begin{array}{l}
x_{1112}=x_{811}+l_{11} \cos \varphi_{11} \\
y_{1112}=x_{811}+l_{11} \sin \varphi_{11}
\end{array},\left\{\begin{array}{l}
\dot{x}_{1112}=0 \\
\dot{y}_{1112}=\dot{y}_{811}+l_{11} \dot{\varphi}_{11} \cos \varphi_{11}
\end{array},\right.\right. \\
& \left\{\begin{array}{l}
\ddot{x}_{1112}=0 \\
\ddot{y}_{1112}=\ddot{y}_{81}-l_{11} \dot{\varphi}_{11}^{2} \sin \varphi_{11}+l_{11} \ddot{\varphi}_{11} \cos \varphi_{11}
\end{array}\right.
\end{aligned}
$$

where $L=\left(x_{1112}-x_{811}\right) / l_{11}, \varphi_{11}=2 \arctan \sqrt{(1-L) /(1+L)}$, $\dot{\varphi}_{11}=\dot{x}_{811} /\left(l_{11} \sin \varphi_{11}\right)$,

$\ddot{\varphi}_{11}=\left(\ddot{x}_{811} \sin \varphi_{11}-\dot{x}_{811} \dot{\varphi}_{11} \cos \varphi_{11}\right) /\left(l_{11} \sin ^{2} \varphi_{11}\right)$.

The position, velocity and acceleration of mass center $\mathrm{P}_{11 \mathrm{c}}$ for the linkage 11 can be given by:

$$
\begin{aligned}
& \left\{\begin{array}{l}
x_{11 c}=x_{811}+\xi_{11} \cos \varphi_{11} \\
y_{11 c}=y_{811}+\xi_{11} \sin \varphi_{11}
\end{array}\right. \\
& \left\{\begin{array}{l}
\dot{x}_{11 c}=\dot{x}_{811}-\xi_{11} \dot{\varphi}_{11} \sin \varphi_{11} \\
\dot{y}_{11 c}=\dot{y}_{811}+\xi_{11} \dot{\varphi}_{11} \cos \varphi_{11}
\end{array}\right. \\
& \left\{\begin{array}{l}
\ddot{x}_{11 c}=\ddot{x}_{811}-\xi_{11} \dot{\varphi}_{11}^{2} \cos \varphi_{11}-\xi_{11} \ddot{\varphi}_{11} \sin \varphi_{11} \\
\ddot{y}_{11 c}=\ddot{y}_{811}-\xi_{11} \dot{\varphi}_{11}^{2} \sin \varphi_{11}+\xi_{11} \ddot{\varphi}_{11} \cos \varphi_{11} .
\end{array}\right.
\end{aligned}
$$

\section{A.2 Dynamic analysis of MLTM}

Dynamic analysis diagram of MLTM is shown in Fig. A.2. Separating the main slider 10 to analyze the forces acting on it, the force sketch of the main slider is shown in Fig. A.2(a). The main slider 10 is acted by binding force, inertial force and piling force, which constitutes the force balance relationship of main slider 10. Then,

$$
\left\{\begin{array}{l}
F_{x 910}-F_{x y^{\prime} 10}=0 \\
F_{y 910}+F_{y y^{\prime} 10}-m_{10} a-m_{10} g+P=0
\end{array}\right.
$$

where $F_{x 910}=F_{x 9^{\prime} 10}$.

The reaction force on slider 10 in the vertical direction can be obtained.

$$
F_{y 910}=\left(m_{10} a+m_{10} g-P\right) / 2 .
$$

Analyzing the forces acting on the linkage 9, the force sketch of the linkage 9 is shown in Fig. A.2(b). The force balance relationship of the linkage 9 is given by:

$$
\left\{\begin{array}{l}
F_{x 9}-F_{x 109}-m_{9} \ddot{x}_{9 c}=0 \\
F_{y 9}-F_{y 109}-m_{9} \ddot{y}_{9 c}-m_{9} g=0 \\
-F_{x 109}\left(y_{78}-y_{910}\right)+F_{y 109}\left(x_{78}-x_{910}\right)-m_{9} \ddot{x}_{9 c}\left(y_{78}-y_{9 c}\right) \\
\quad+m_{9}\left(\ddot{y}_{9 c}+g\right)\left(x_{78}-x_{9 c}\right)=J_{9} \ddot{\varphi}_{9}
\end{array}\right.
$$

where $J_{9}=m_{9} l_{9}^{2} / 3, F_{x 109}=F_{x 910}, F_{y 109}=F_{y 910}$.

Solving Eq. (A.27) yields the reaction forces of $F_{x 109}, F_{x 9}$ and $F_{y 9}$.

$$
\begin{aligned}
F_{x 109}= & {\left[F_{y 109}\left(x_{78}-x_{910}\right)-m_{9} \ddot{x}_{9 c}\left(y_{78}-y_{9 c}\right)\right.} \\
& \left.+m_{9}\left(\ddot{y}_{9 c}+g\right)\left(x_{78}-x_{9 c}\right)-J_{9} \ddot{\varphi}\right] /\left(y_{78}-y_{910}\right) \\
F_{x 9}= & F_{x 109}+m_{9} \ddot{x}_{9 c} \\
F_{y 9}= & F_{y 109}+m_{9}\left(\ddot{y}_{9 c}+g\right) .
\end{aligned}
$$

The force balance relationship of the slider 12 shown in Fig. A.2(c) is also expressed as:

$$
\left\{\begin{array}{l}
F_{x 1112}-Q_{1}=0 \\
F_{y 1112}-m_{12} \ddot{y}_{1112}-m_{12} g=0
\end{array}\right.
$$

where $F_{x 1112}=F_{x 1211}, F_{y 1112}=F_{y 1211}$

The reaction force on slider 12 in the vertical direction can be obtained,

$$
F_{y 1112}=m_{12}\left(\ddot{y}_{1112}+g\right) \text {. }
$$

The force balance relationship of the linkage 11 shown in Fig. A.2(d) is expressed as:

$$
\left\{\begin{array}{l}
F_{x 811}-F_{x 1211}-m_{11} \ddot{x}_{11 c}=0 \\
F_{y 811}-F_{y 1211}-m_{11} \ddot{y}_{11 c}-m_{11} g=0 \\
F_{x 1211}\left(y_{1112}-y_{811}\right)-F_{y 1211}\left(x_{1112}-x_{811}\right)+m_{11} \ddot{x}_{11 c}\left(y_{11 c}\right. \\
\left.\quad-y_{811}\right)-m_{11}\left(\ddot{y}_{11 c}+g\right)\left(x_{11 c}-x_{811}\right)=J_{11} \ddot{\varphi}_{11}
\end{array}\right.
$$

where $J_{11}=m_{11} l_{11}^{2} / 3, F_{x 811}=F_{x 118}, F_{y 811}=F_{y 118}$.

Solving Eq. (A.31) yields the reaction forces of $F_{x 1211}$, $F_{x 811}$ and $F_{y 811}$.

$$
\begin{aligned}
F_{x 1211} & =\left[F_{y 1211}\left(x_{1112}-x_{811}\right)-m_{11} \ddot{x}_{11 c}\left(y_{11 c}-y_{811}\right)\right. \\
& \left.+m_{11} \ddot{y}_{11 c}\left(x_{11 c}-x_{811}\right)+J_{11} \ddot{\varphi}_{11}\right] /\left(y_{1112}-y_{811}\right) \\
F_{x 811} & =F_{x 1211}+m_{11} \ddot{x}_{11 c} \\
F_{y 811} & =F_{y 1211}+m_{11} \ddot{y}_{11 c}+m_{11} g .
\end{aligned}
$$

Similarly, separating the linkage 8 to analyze the forces acting on it, the force balance relationship of the linkage 8 shown in Fig. A.2(e) is given by:

$$
\left\{\begin{array}{l}
F_{x 8}+F_{x 18}-F_{x 118}-m_{8} \ddot{x}_{8 c}=0 \\
F_{y 8}+F_{y 18}-F_{y 118}-m_{8} \ddot{y}_{8 c}-m_{8} g=0 \\
F_{x 8}\left(y_{18}-y_{78}\right)+F_{y 8}\left(x_{78}-x_{18}\right)-m_{8} \ddot{x}_{8 c}\left(y_{18}-y_{8 c}\right) \\
\quad-m_{8}\left(\ddot{y}_{8 c}+g\right)\left(x_{8 c}-x_{18}\right)=J_{8} \ddot{\varphi}_{8}
\end{array}\right.
$$

where $J_{8}=m_{8} l_{8}^{2} / 3$.

Separating the linkage 7 to analyze the forces acting on it, the force balance relationship of the linkage 7 shown in Fig. A.2(f) is given by:

$$
\begin{aligned}
& F_{x 57}-F_{x 7}-m_{7} \ddot{x}_{7 c}=0 \\
& F_{y 57}-F_{y 7}-m_{7}\left(\ddot{y}_{7 c}+g\right)=0
\end{aligned}
$$




$$
\begin{gathered}
-F_{x 7}\left(y_{57}-y_{78}\right)+F_{y 7}\left(x_{57}-x_{78}\right)-m_{7} \ddot{x}_{7 c}\left(y_{57}-y_{7 c}\right) \\
+m_{7}\left(\ddot{y}_{7 c}+g\right)\left(x_{57}-x_{7 c}\right)=J_{7} \ddot{\varphi}_{7}
\end{gathered}
$$

where $J_{7}=m_{7} l_{7}^{2} / 3$.

Solving Eqs. (A.34a) and (A.34b) yields the reaction forces of $F_{x 57}$ and $F_{y 57}$.

$$
\left\{\begin{array}{l}
F_{x 57}=F_{x 7}+m_{7} \ddot{x}_{7 c} \\
F_{y 57}=F_{y 7}+m_{7}\left(\ddot{y}_{7 c}+g\right) .
\end{array}\right.
$$

The force balance relationship at the conjunct joint among linkages 7, 8 and 9 can be expressed as:

$$
\left\{\begin{array}{l}
F_{x 9}+F_{x 8}-F_{x 7}=0 \\
F_{y 9}+F_{y 8}-F_{y 7}=0 .
\end{array}\right.
$$

Solving Eqs. (A.33), (A.34c) and (A.36) yields the reaction forces of $F_{x 7}, F_{y 7}, F_{x 8}, F_{y 8}, F_{x 18}$ and $F_{y 18}$.

$$
\left\{\begin{aligned}
F_{x 8}= & {\left[Z_{2}\left(x_{57}-x_{78}\right)-Z_{1}\left(x_{78}-x_{18}\right)\right] /\left[\left(y_{57}-y_{78}\right)\right.} \\
& \left.\left(x_{78}-x_{18}\right)+\left(y_{18}-y_{78}\right)\left(x_{57}-x_{78}\right)\right] \\
F_{y 8}= & {\left[Z_{2}\left(y_{57}-y_{78}\right)+Z_{1}\left(y_{18}-y_{78}\right)\right] /\left[\left(x_{57}-x_{78}\right)\right.} \\
& \left.\left(y_{18}-y_{78}\right)+\left(x_{78}-x_{18}\right)\left(y_{57}-y_{78}\right)\right] \\
F_{x 18}= & F_{x 118}+m_{8} \ddot{x}_{8 c}-F_{x 8} \\
F_{y 18}= & F_{y 118}+m_{8}\left(\ddot{y}_{8 c}+g\right)-F_{y 8} \\
F_{x 7}= & F_{x 9}+F_{x 8} \\
F_{y 7}= & F_{y 9}+F_{y 8}
\end{aligned}\right.
$$

where

$$
\begin{aligned}
Z_{1}= & J_{7} \ddot{\varphi}_{7}+m_{7} \ddot{x}_{7 c}\left(y_{57}-y_{7 c}\right)-m_{7}\left(\ddot{y}_{7 c}+g\right) \\
& \left(x_{57}-x_{7 c}\right)+F_{x 9}\left(y_{57}-y_{78}\right)-F_{y 9}\left(x_{57}-x_{78}\right) \\
Z_{2}= & J_{8} \ddot{\varphi}_{8}+m_{8} \ddot{x}_{8 c}\left(y_{18}-y_{8 c}\right)+m_{8}\left(\ddot{y}_{8 c}+g\right)\left(x_{8 c}-x_{18}\right) .
\end{aligned}
$$

Analyzing the forces acting on the linkage 5, the force sketch of the linkage 5 is shown in Fig. A.2(g). The force balance relationship of the linkage 5 is given by:

$$
\left\{\begin{array}{l}
F_{x 45}+F_{x 65}-F_{x 75}-m_{5} \ddot{x}_{5 c}=0 \\
F_{y 45}+F_{y 65}-F_{y 75}-m_{5} \ddot{y}_{5 c}-m_{5} g=0 \\
-F_{x 75}\left(y_{54}-y_{57}\right)+F_{x 65}\left(y_{54}-y_{56}\right)-F_{y 75} x_{57}+F_{y 65} x_{56} \\
\quad-m_{5} \ddot{x}_{5 c}\left(y_{54}-y_{5 c}\right)-m_{5}\left(\ddot{y}_{5 c}+g\right) x_{5 c}=J_{5} \ddot{\varphi}_{5}
\end{array}\right.
$$

where $J_{5}=m_{5} l_{5}^{2} / 3, F_{x 75}=F_{x 57}, F_{y 75}=F_{y 57}$.

Analyzing the forces acting on the linkage 6, the force sketch of the linkage 6 is shown in Fig. A.2(h). The force balance relationship of the linkage 6 is given by:

$$
\left\{\begin{array}{l}
F_{x 56}-F_{x 16}-m_{6} \ddot{x}_{6 c}=0 \\
F_{y 16}-F_{y 56}-m_{6} \ddot{y}_{6 c}-m_{6} g=0 \\
F_{x 56}\left(y_{56}-y_{16}\right)-F_{y 56} x_{56}+m_{6} \ddot{x}_{6 c}\left(y_{6 c}-y_{16}\right) \\
\quad-m_{6}\left(\ddot{y}_{6 c}+g\right) x_{6 c}=J_{6} \ddot{\varphi}_{6}
\end{array}\right.
$$

where $J_{6}=m_{6} l_{6}^{2} / 3, F_{x 56}=F_{x 65}, F_{y 56}=F_{y 65}$.

Solving Eqs. (A.38) and (A.39) yields the reaction forces of $F_{x 45}, F_{y 45}, F_{x 65}, F_{y 65}, F_{x 16}$ and $F_{y 16}$.

$$
\begin{aligned}
F_{x 65}= & \left(Z_{3}+Z_{4}\right) /\left(y_{54}-2 y_{56}+y_{16}\right) \\
F_{y 65}= & {\left[Z_{3}\left(y_{56}-y_{16}\right)+Z_{4}\left(y_{54}-y_{56}\right)\right] / x_{56} / } \\
& \left(2 y_{56}-y_{16}-y_{54}\right) \\
F_{x 45}= & F_{x 75}+m_{5} \ddot{x}_{5 c}+F_{x 65} \\
F_{y 45}= & F_{y 75}+m_{5}\left(\ddot{y}_{5 c}+g\right)-F_{y 65} \\
F_{x 16}= & F_{x 56}-m_{6} \ddot{x}_{6 c} \\
F_{y 16}= & m_{6}\left(\ddot{y}_{6 c}+g\right)+F_{y 56}
\end{aligned}
$$

where

$$
\begin{aligned}
Z_{3}= & J_{5} \ddot{\varphi}_{5}+F_{y 75} x_{57}+m_{5} \ddot{x}_{5 c}\left(y_{54}-y_{5 c}\right) \\
& +m_{5}\left(\ddot{y}_{5 c}+g\right) x_{5 c}+F_{x 75}\left(y_{54}-y_{57}\right) \\
Z_{4}= & J_{6} \ddot{\varphi}_{6}-m_{6} \ddot{x}_{6 c}\left(y_{6 c}-y_{16}\right)+m_{6}\left(\ddot{y}_{6 c}+g\right) x_{6 c} .
\end{aligned}
$$

The force balance relationship of the slider 4 shown in Fig. A.2(i) is also expressed as:

$$
\left\{\begin{array}{l}
F_{x 5^{\prime} 4}+Q_{2}-F_{x 54}-F_{x 34}=0 \\
F_{y 34}-F_{y 54}-F_{y 5^{\prime} 4}-m_{4} \ddot{y}_{34}-m_{4} g=0
\end{array}\right.
$$

where $F_{x 5^{\prime} 4}=F_{x 54}, F_{y 54}=F_{y 5^{\prime} 4}, F_{x 45}=F_{x 54}, F_{y 45}=F_{y 54}$.

Solving Eq. (A.41) yields the reaction forces of $F_{x 34}$ and $F_{y 34}$.

$$
\left\{\begin{array}{l}
F_{x 34}=Q_{2} \\
F_{y 34}=2 F_{y 54}+m_{4}\left(\ddot{y}_{34}+g\right) .
\end{array}\right.
$$

Separating the linkage 3 to analyze the forces acting on it, the force balance relationship of the linkage 3 shown in Fig. A.2(j) is given by:

$$
\left\{\begin{array}{l}
F_{x 43}-F_{x 23}-m_{3} \ddot{x}_{3 c}=0 \\
F_{y 23}-F_{y 43}-m_{3} \ddot{y}_{3 c}-m_{3} g=0 \\
F_{x 43}\left(y_{32}-y_{34}\right)+F_{y 43} x_{23}-m_{3} \ddot{x}_{3 c}\left(y_{32}-y_{3 c}\right) \\
\quad-m_{3}\left(\ddot{y}_{3 c}+g\right)\left(x_{3 c}-x_{32}\right)=J_{3} \ddot{\varphi}_{3}
\end{array}\right.
$$

where $J_{3}=m_{3} l_{3}^{2} / 3, F_{x 43}=F_{x 34}, F_{y 34}=F_{y 43}$.

Solving Eq. (A.43) yields the reaction forces of $F_{x 43}$, $F_{x 23}$ and $F_{y 23}$.

$$
\left\{\begin{aligned}
F_{x 43}= & {\left[-F_{y 43} x_{23}+m_{3} \ddot{x}_{3 c}\left(y_{32}-y_{3 c}\right)+m_{3}\left(\ddot{y}_{3 c}+g\right)\right.} \\
& \left.\left(x_{3 c}-x_{32}\right)+J_{3} \ddot{\varphi}_{3}\right] /\left(y_{32}-y_{34}\right) \\
F_{x 23}= & F_{x 43}-m_{3} \ddot{x}_{3 c} \\
F_{y 23}= & F_{y 43}+m_{3}\left(\ddot{y}_{3 c}+g\right) .
\end{aligned}\right.
$$


Similarly, separating the crank shaft 2 to analyze the forces acting on it, the force balance relationship of the crank shaft 2 shown in Fig. A.2(k) is given by:

$$
\left\{\begin{array}{l}
F_{x 32}-F_{x 12}-m_{2} \ddot{x}_{2 c}=0 \\
F_{y 12}-F_{y 32}-m_{2} \ddot{y}_{2 c}-m_{2} g=0
\end{array}\right.
$$

where $J_{2}=m_{2} l_{2}^{2} / 3, F_{x 32}=F_{x 23}, F_{y 23}=F_{y 32}$.

Solving Eq. (A.45) yield the reaction forces of $F_{x 12}$ and $F_{y 12}$.

$$
\left\{\begin{array}{l}
F_{x 12}=F_{x 32}-m_{2} \ddot{x}_{2 c} \\
F_{y 12}=F_{y 32}+m_{2}\left(\ddot{y}_{2 c}+g\right) .
\end{array}\right.
$$

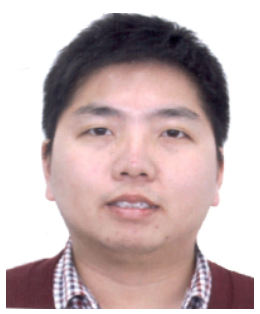

Enlai Zheng received his B.S. and Ph.D. degrees in Mechanical Engineering from Nanjing Institute of Technology and Southeast University in 2008 and 2013, respectively. He is currently an Associate Professor in the Faculty of Mechanical Engineering in Nanjing Agricultural University, and a visiting scholar in the Faculty of Engineering and the Environment in University of Southampton. His research field is mainly focused on dynamic design and control of machine.

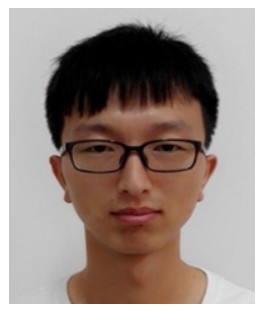

Jin Zhang received his B.S. degree in Mechanical Design, Manufacturing and Automation from College of Engineering, Nanjing Agricultural University in 2016. $\mathrm{He}$ is currently a postgraduate student and pursuing for M.S. degree in Mechanical Engineering from Nanjing Agricultural University. His research interest is thermal error modelling, analysis and compensation of machine.

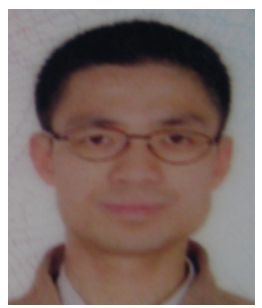

Yue Zhu received his B.S. and M.S. degrees in Mechanical Engineering from Jiangsu University of Science and Technology, and Southwest University of Science and Technology in 1998 and 2007. He received his Ph.D. degree in Mechanical Engineering from Nanjing University of Aeronautics \& Astronautics in 2011. He is currently a Lecturer in the Faculty of Mechanical Engineering in Nanjing Agricultural University. His research interest is focused on model updating and validation, and vibration control.

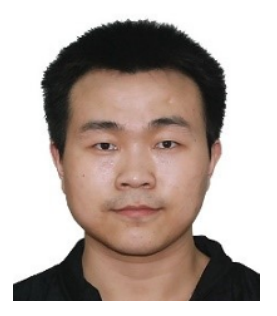

Xiao Zhao received his B.S. and Ph.D. degrees in Materials Science and Engineering from Huazhong University of Science and Technology in 2011 and 2016, respectively. He is currently a Research Fellow in the Faculty of Engineering and the Environment in University of Southampton. His research interest is focused on thermal error modelling and compensation of mechanical system.

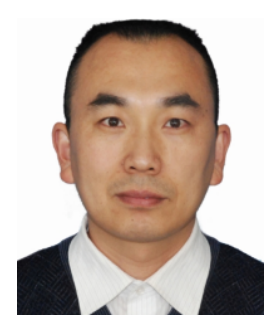

Xiangze Lin received his B.S. and M.S. degrees from Southeast University in 2000 and 2006. He received his Ph.D. degree from Nanjing University of Science and Technology in 2012. He worked as a Visiting Scholar in University of Texas from May 2015 to May 2016. He is currently an Associate Professor in the College of Engineering, Nanjing Agricultural University. His main research interests include dynamic design and control of machine.

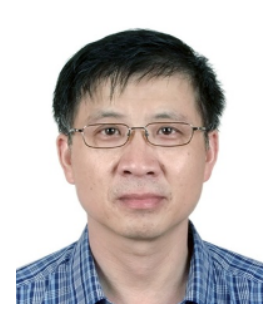

Min Kang received his B.S. and M.S. degrees in Mechanical Engineering from Northeastern University and Xi'an Jiaotong University in 1986 and 1989, respectively. He received his $\mathrm{Ph} . \mathrm{D}$. degree in Mechanical Engineering from Nanjing University of Aeronautics and Astronautics in 2003. He is currently a Professor in the College of Engineering in Nanjing Agricultural University. His research interest is focused on design and control of machining technology and machine. 